Atmos. Chem. Phys. Discuss., 9, 17963-18019, 2009 www.atmos-chem-phys-discuss.net/9/17963/2009/ (C) Author(s) 2009. This work is distributed under the Creative Commons Attribution 3.0 License.

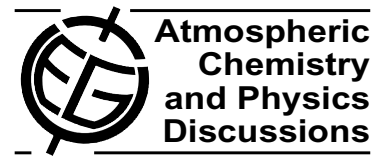

This discussion paper is/has been under review for the journal Atmospheric Chemistry and Physics (ACP). Please refer to the corresponding final paper in $A C P$ if available.

\title{
Influence of aerosols on the formation and development of radiation fog
}

\author{
J. Rangognio ${ }^{1}$, P. Tulet ${ }^{1,3}$, T. Bergot ${ }^{1}$, L. Gomes ${ }^{1}$, O. Thouron ${ }^{1}$, and M. Leriche ${ }^{2}$ \\ ${ }^{1}$ GAME/CNRM (Météo-France, CNRS), Toulouse, France \\ ${ }^{2}$ Laboratoire d'Aérologie/UMR 5560/CNRS-UPS, Toulouse, France \\ ${ }^{3}$ Lacy/UMR 8105/Université de la Réunion, Saint-Denis, France \\ Received: 4 August 2009 - Accepted: 14 August 2009 - Published: 1 September 2009 \\ Correspondence to: J. Rangognio (jerome.rangognio@laposte.net) \\ Published by Copernicus Publications on behalf of the European Geosciences Union.
}

17963

\begin{abstract}
This paper assesses the impact of aerosol properties on the formation and the development of radiation fog. Simulations were performed using the Meso-NH meteorological model including the ORILAM aerosol scheme coupled with a two-moment 5 microphysical cloud scheme (number concentration of cloud droplets and cloud water content). The activation scheme used was taken from the work of Abdul-Razzak and Ghan (2004). "Off-line" sensitivity analysis of CCN (Cloud Condensation Nuclei) activation was performed on number, median diameter and chemical compounds of aerosols. During this "off-line" study, the interactions with the other physical processes (e.g. radia10 tive) were not taken into account since the cooling rate was imposed. Different regimes of $\mathrm{CCN}$ activation and a critical value of aerosol number concentration were found. This critical aerosol number corresponds to the maximum of activated cloud droplets for a given cooling rate and given aerosol chemical properties. As long as the aerosol number concentration is below this critical value, the cloud droplet number increases 15 when the aerosol number increases. But when the aerosol number concentration exceeds this critical value, the cloud droplet number decreases when aerosol number increases. A sensitivity study on aerosol chemical composition showed that the CCN activation was limited in the case of hydrophilic aerosol composed of material with a solubility in the $10 \%$ range. An event observed during the ParisFOG field experiment was simulated. This case took place in the polluted sub-urban area of Paris (France) characterized by particle concentrations of 17000 aerosols per $\mathrm{cm}^{3}$. 1D simulations successfully reproduced the observed temporal evolution of the fog layer. Beyond the initial fog formation at the surface, cloud droplet formation occurred at the top of the fog layer where the cooling rate was maximum, reaching more than $-10 \mathrm{Kh}^{-1}$. These

25 simulations confirm that the aerosol particle number concentration is a key parameter for the accurate prediction of the microphysical properties of a fog layer and also influences the vertical development of fog. The important of the interaction between microphysical and radiative processes is illustrated, showing how the life cycle of a fog
\end{abstract}


layer is determined by the CCN number concentration and chemical properties.

\section{Introduction}

Aerosols and clouds play a major role in environmental, meteorological and climatic processes, and the aerosol-cloud interactions are now identified as a key challenge

5 for the understanding of climate change. Vautard et al. (2009) estimates that the reduction in low-visibility conditions could have contributed about $20 \%$ on average to Europe's recent daytime warming and about $50 \%$ to eastern European warming. More locally, fog has a significant impact on economic and safety aspects. Timely and accurate forecasts of reduced visibility are necessary for the agencies responsible for road

10 safety, search and rescue operations and air traffic management. Nevertheless, fog forecasting by meteorological services is still a difficult issue. For instance, Pagowski et al. (2004) studied a fog episode related to a major traffic accident in Canada and pointed out that the forecasting of fog was very difficult because of its high variability and because of the complex interactions between physical processes occurring inside

15 a fog layer. The fog life cycle is determined by thermodynamic, dynamic, radiative, and microphysical processes, and by surface conditions. One of the particularities of fog is its development within the surface boundary layer, in contact with the ground, where aerosol concentrations are the highest and surface heterogeneities imply complex heat, water, radiative and chemical fluxes.

20 Radiation fog is mainly formed during the night above continental surfaces under high pressure systems. The radiative cooling of the surface can lead to saturated conditions and hence to cloud droplet formation. The life cycle of radiation fog can be decomposed into three steps according to the behaviour of the turbulent kinetic energy: onset, vertical development and dissipation (e.g. Nakanishi 2000). Only the two first 25 steps will be studied in this work.

Cloud droplet formation occurs with heterogeneous nucleation onto aerosol particles (e.g. Pruppacher and Klett 1997). Particles that serve as nuclei upon which water

17965

vapour condenses are called cloud condensation nuclei (CCN). The parametrization of CCN activation is well developed (e.g. Twomey 1959; Ghan et al. 1993; Abdul-Razzak et al. 1998; Cohard and Pinty 2000a,b; Nenes and Seinfeld 2003; Cheng et al. 2007), since the activation process directly links microphysical aerosols and clouds. The size 5 distribution and chemical composition of aerosols heavily influence CCN activation. Atmospheric aerosols are largely composed of soluble inorganic species but it is now known that a significant proportion of soluble matter (ranging from $20 \%$ up to $70 \%$ of the total soluble mass in some cases) also consists of organic compounds (e.g. Saxena and Hildemann 1996; Zappoli et al. 1999). Some organic compounds are surface 10 active (surfactants) and their presence within particle solutions can significantly affect CCN activation (e.g. Shulman et al. 1996; Li et al. 1998; Facchini et al. 2000).

Numerous numerical models have been developed for the description of fog physics (e.g. Brown and Roach 1976; Brown 1980; Duynkerke 1991; Bergot and Guedalia 1994). Some studies also show that the interaction between aerosol and fog is an im15 portant issue (Pandis and Seinfeld, 1989a,b; Seinfeld et al., 1992; Bott, 1991; Bott and Carmichael, 1993). In the fog life cycle, the condensation process and cloud droplet sedimentation are crucial. Detailed understanding and modelling of the fine microphysical processes taking place inside a fog layer has been limited by the lack of suitable sets of dynamic, turbulent, radiative and microphysical measurements. Nevertheless,

20 during the last few decades, several studies have observed and studied the chemistry of fog, in particular the interaction of fog with black carbon (Badarinath et al., 2007; Husain et al., 2007) and with sulphate (Seinfeld et al., 1992; Reilly et al., 2001), and the chemistry of cloud droplets in fog (Fisak et al., 2002; Blando and Turpin, 2000; Moore et al., 2004; Aikawa et al., 2007).

25 Many previous works have studied CCN activation inside stratocumulus or cumulus, i.e. associated with a significant cooling rate mainly forced by a vertical velocity. The specificity of this work is to study CCN activation in foggy conditions. Therefore, the framework is relatively different to past studies on activation. Firstly, the fog is a cloud in contact with the ground where aerosol concentrations are the highest. Secondly, 
the cooling rate is mainly associated with radiative cooling and, consequently, is different from the cooling of other boundary layer clouds associated with vertical velocity. Moreover, this cooling rate is maximum at the top of the fog layer, leading to maximum production of liquid water near the top of the fog.

5 Aerosols influence the fog life cycle in a complex way. The number, size and chemical properties of aerosol particles are key properties in the activation processes. Consequently, the aerosol characteristics directly affect the microphysical properties of a fog layer (number and size of the fog droplets). But the microphysical properties of a fog layer indirectly influence the life cycle of the fog through the interactions between

10 microphysical, dynamic and radiative processes.

The primary objective of this work was to analyse CCN activation in foggy conditions and to quantify the effects of the aerosol size distribution, concentration and chemical composition on the formation and the evolution of the vertical structure of fog.

In a first step, sensitivity tests of the activation processes only were performed. The

15 goal of these so-called "off-line" simulations was to isolate the influences of aerosol properties and atmospheric cooling rates on the $\mathrm{CCN}$ activation. In this approach, the interactions with the other physical processes (such as radiative) were not taken into account since the cooling rate was imposed. This study focused on the sensitivity of aerosol activation to differences in the air mass encountered above a continental sur-

20 face. In the second step, an observed fog case was modelled in order to study the complex interactions involved in a fog layer. To achieve this objective, a series of simulations were performed, based on data gathered during the ParisFOG field experiment (Bergot et al., 2008). Comprehensive 1-D simulations were made with the Meso-NH numerical mesoscale model (Lafore et al., 1998), in which the ORILAM aerosol scheme (Tulet

25 et al., 2005) was coupled with the two-moment microphysical scheme from the work of Khairoutdinov and Kogan (2000) through the activation scheme of Abdul-Razzak and Ghan (2004). This set of 1-D simulations served as the basis for a comprehensive study of the interactions between aerosol properties, and microphysical and dynamic processes taking place during the life cycle of fog. Complex interactions between short

17967

wave radiation, aerosols and cloud droplets occur during the dissipation stage. The influence of aerosol on the dissipation of a fog layer is not studied in this work, and will be the subject of a future study.

The numerical models used in this study are described in Sect. 2 while observations 5 are described in Sect. 3. Section 4 illustrates the sensitivity of activation processes to aerosol properties obtained from the "off-line" simulations. Results from 1-D simulations of a radiation fog event observed during the ParisFOG experiment are discussed in section 5. And, finally, Sect. 6 summarizes the results.

\section{Numerical tools}

\section{2.1 Meso-NH Model and the 2-moment warm microphysical parameterization}

Meso-NH is a meteorological model jointly developed by CNRM/GAME (Météo-France) and the Laboratoire d'Aérologie (CNRS) (Lafore et al., 1998). Meso-NH simulates small-scale (Large Eddy Simulation, LES type, horizontal resolution of a few meters) to synoptic-scale (horizontal resolution of several tens of kilometres) features and can

15 be run in a two-way nested mode involving up to eight nested grids. Different sets of parameterizations have been introduced for the representation of various physical influences (for details, see http://mesonh.aero.obs-mip.fr). For this study, the sub-grid scale turbulence was parameterized with a 1.5 closure for the vertical fluxes using the prognostic turbulent kinetic energy. The turbulence scheme used was that of Cuxart

20 et al. (2000) and the turbulent mixing length was from Bougeault and Lacarrère (1989). Details of the shortwave radiation code are given in Morcrette (1989) while the longwave radiation scheme was the Rapid Radiation Transfer Model (Mlawer et al., 1997). The cloud shortwave optical properties are determined following Fouquart (1987) and the cloud longwave optical properties were treated with Smith and Shi (1992)'s for-

25 mulation. The coupling between the atmosphere and the underlying surface was based on the ISBA scheme (Interactions between the Soil Biosphere and Atmosphere, 
Noilhan and Planton 1989), extended by the TEB (Town Energy Balance) parameterization (Masson, 2000) for urban-atmosphere interaction. The numerical model has been validated previously for severals cases of fog and low-level cloud (e.g. Bergot et al. 2007; Sandu et al. 2008).

$5 \quad$ The cloud microphysics were computed using a bulk microphysics parameterization based on the Kessler scheme (Kessler, 1969). The liquid water was separated into cloud water and precipitation. The 2-moment warm microphysical parameterization was taken from the work of Khairoutdinov and Kogan (2000), and extended by Geoffroy (2007). The number concentration of cloud droplets (N) and the cloud water 10 content $(q)$ were prognostic. The parameterization of microphysical processes (drizzle droplet sedimentation, autoconversion, accretion, condensation and vaporisation) are detailed in Khairoutdinov and Kogan (2000) and Geoffroy (2007). A key aspect of the parameterization was the assumption that the cloud droplet distribution followed the generalized gamma distribution:

${ }_{15} n(\mathrm{D})=\mathrm{N} \frac{\alpha}{\Gamma(u)} \lambda^{\alpha u} \mathrm{D}^{\alpha u-1} \exp \left(-(\lambda \mathrm{D})^{\alpha}\right)$,

where

$\lambda=\left(\frac{\pi}{6} \rho_{w} \frac{\Gamma(u+3 / \alpha)}{\Gamma} \frac{N}{q}\right)^{1 / 3}$

$\Gamma$ is the gamma function (Press et al., 1992), $\mathrm{N}$ the cloud droplet concentration, $\mathrm{D}$ the diameter of the cloud droplet, $q$ the liquid water content, and $\rho_{w}$ the density of liquid 20 water. $\alpha$ and $v$ are empirical coefficients set to 1 and 3 respectively, as derived from observations.

\subsection{The Organic Inorganic Log-normal Aerosol Module (ORILAM)}

ORILAM (Tulet et al., 2005) is a three-moment log-normal aerosol scheme based on number, mass composition and standard deviation. This aerosol module is coupled

17969

with the ReLACS2 chemical scheme (Tulet et al., 2006) based on the CACM scheme (Griffin et al., 2002). ORILAM takes a range of internally mixed aerosol compounds into account, such as BC (black carbon, viewed as soot in our study), OC (primary organic aerosol), $\mathrm{H}_{2} \mathrm{O}$ (water), $\mathrm{NH}_{4}^{+}$(ammonium), $\mathrm{NO}_{3}^{-}$(nitrates), $\mathrm{SO}_{4}^{2-}$ (sulphates) and ten 5 different SOA types as defined by Griffin et al. (2003). The log-normal approach is given for each mode by:

$n\left(r_{a p}\right)=\frac{\mathrm{N}_{r}}{\sqrt{2 \pi} \ln \sigma} \exp \left(-\frac{\ln ^{2}\left(\frac{r_{a p}}{r_{m}}\right)}{2 \ln ^{2}(\sigma)}\right)$,

where $\mathrm{N}_{r}$ is the aerosol number concentration (in particles $\mathrm{cm}^{-3}$ ), $\mathrm{r}_{a p}$ is the aerosol particle radius, $r_{m}$ is the geometric mean radius, and $\sigma$ is the geometric standard de10 viation. The multimodal aerosol distribution computed by ORILAM is used by the CCN activation scheme described in the next section.

\subsection{The CCN activation scheme}

The coupling between Meso-NH and ORILAM consists of using the atmospheric cooling rate computed in Meso-NH and the aerosol chemical composition and size distri15 bution computed by ORILAM to estimate the supersaturation and the number of activated CCN. The aerosol activation scheme used is that of Abdul-Razzak and Ghan (2004), which is an extension of Abdul-Razzak et al. (1998) and Abdul-Razzak and Ghan (2000). A detailed description of the activation scheme can be found in AbdulRazzak and Ghan (2004) and only the main characteristics of this parameterization will be described here.

The purpose of this parameterization, based on the Köhler theory (Köhler, 1936) is to determine the fraction $\frac{\mathrm{N}}{\mathrm{N}_{a}}$ of activated aerosol particles composed of an internal 
chemical mixture of organic and inorganic compounds (Eq. 4):

$\frac{\mathrm{N}}{\mathrm{N}_{\mathrm{a}}}=\frac{1}{2} \operatorname{ert} c\left(\frac{2 \ln \left(\frac{\mathrm{S}_{m}}{\mathrm{~S}_{\max }}\right)}{3 \sqrt{2} \ln \sigma}\right)$

where $S_{m}$ and $S_{\max }$ are defined further.

In this activation scheme, the influence of organic surfactants is considered by mod-

5 ifying the Köhler curve decreasing the value of surface tension. According to Shulman et al. (1996), the Raoult term (noted B) for internal chemical mixtures can be expressed by assuming additive behaviour of the two compounds and can be reformulated as follows:

$\mathrm{B}=\frac{\mathrm{M}_{w} \rho_{a p}}{\rho_{w}}\left[\frac{v_{\mathrm{sal}} \phi_{\mathrm{sal}}\left(1-\epsilon_{m}\right)}{\mathrm{M}_{\mathrm{sal}}}+\frac{v_{\mathrm{stt}} \phi_{\mathrm{sft}} \epsilon_{m}}{\mathrm{M}_{\mathrm{sft}}}\right]=\mathrm{B}_{\mathrm{sal}}+\mathrm{B}_{\mathrm{sft}}$

10 where $\epsilon_{m}$ is the soluble mass fraction of the organic surfactants over the total soluble mass of aerosol, $\mathrm{M}_{w}$ is the molecular weight of $\mathrm{H}_{2} \mathrm{O}, \rho_{w}$ is the density of $\mathrm{H}_{2} \mathrm{O}, \phi_{\text {sal }}$ and $\phi_{\text {sft }}$ are the osmotic coefficients of the salts and the surfactants respectively, $v_{\text {sal }}$ and $v_{\text {sft }}$ are the number of equivalent ions into which a molecule dissociates into salts and surfactants respectively, $\rho_{a p}$ is the density of dry aerosol particles and $\mathrm{M}_{\mathrm{sal}}$ and

${ }_{15} \mathrm{M}_{\mathrm{sft}}$ are the molecular weight of salts and surfactants respectively. $B_{\text {sal }}$ and $B_{\text {sft }}$ are the contributions of the salt and the surfactant to the Raoult term B.

This parameterization takes account of the effect of aerosol composition (both inorganic and organic) on hygroscopicity (Raoult term, $B$ ) and on surface tension (Kelvin term, $A$ ). The activated aerosol concentration calculated by Eq. 4 corresponds to the 20 concentration of cloud droplets formed. The critical supersaturation of the smallest aerosol particle activated is equal to the maximum supersaturation $S_{\max }$ :

$S_{\max }=\sqrt{\frac{S_{m}^{2}}{f(\ln \sigma)\left(\frac{\varsigma}{\eta}\right)^{\frac{3}{2}}+g(\ln \sigma)\left(\frac{S_{m}^{2}}{(\eta+3 \varsigma)^{\frac{3}{4}}}\right)}}$

17971

where

$S_{m}=\sqrt{\frac{4 A^{3}}{27 B r_{m}^{3}}}$

is the critical supersaturation for the activation of particles with dry radius $r_{m} . f(\ln \sigma)$ and $\mathrm{g}(\ln \sigma)$ are two functions of $\sigma ; \zeta$ and $\eta$ are two dimensionless terms depending on

5 the atmospheric cooling rate (due to updraft velocity of an air parcel rising adiabatically in Abdul-Razzak and Ghan 2004 for details). For radiation fog, radiative cooling is the main mechanism driving the supersaturation. In order to take this effect into account, an additional term depending on the diabatic cooling rate in added.

10 The critical supersaturation (Eq. 7), and consequently the CCN activation, is driven by the chemical composition (effect on the Raoult term, $B$ ) and by the aerosol size (effect on the Kelvin term, $A$ ). For a given cooling rate, bigger aerosol particles or the presence of salt compounds decrease the critical supersaturation and hence increase the fraction activated.

\section{Observations}

\subsection{ParisFOG Field Experiment}

The six-month ParisFOG fog field experiment was carried out during the 2006-2007 winter season in a suburban area $20 \mathrm{~km}$ south of Paris, France (Bergot et al. 2008 and http://sirta.ipsl.polytechnique.fr/parisfog/). The objectives of ParisFOG were to observe

20 and describe, as thoroughly as possible, several fog events during a winter season and to provide complete information on the various processes taking place during the life cycle of fog (turbulence, microphysics, radiation and surface exchanges). The overall aim of this experiment was thus to improve our understanding and our ability to simulate the life cycle of fog in order to enhance the quality of fog forecasts. The 
present work mainly focuses on the influence of microphysical processes taking place during an episode of dense radiation fog which occurred during the night of 18 to 19 February 2007 (corresponding to the Intensive Observation Period, IOP 13, of the experiment). Given the focus of the study, only the microphysical instruments will be

5 presented here. A complete description of ParisFOG instrumentation is given in Bergot et al. (2008) or on the web site dedicated to this experiment.

\subsection{Microphysical instrumentation}

The particle number size distribution within a diameter between 10 and $500 \mathrm{~nm}$ was obtained from a Scanning Mobility Particle Sizer (SMPS) composed of a long Differ-

10 ential Mobility Analyzer (DMA, model TSI 3081) connected to a Condensation Particle Counter (CPC, model TSI 3025 High Flow) and from an optical particle counter (OPC, model GRIMM 1.109) for a diameter range of 0.25 to $32 \mu \mathrm{m}$. These measurements were performed in an air-conditioned mobile laboratory. The aerosol was sampled via a low-flow $\mathrm{PM}_{2.5}$ inlet at a height of approximately $2 \mathrm{~m}$ and measured for relative hu-

15 midity below $50 \%$ with a 10 -min resolution. Thus, both instruments were considered to operate in dry conditions at a flow rate of $0.51 \mathrm{~min}^{-1}$ and $1.21 \mathrm{~min}^{-1}$ for the DMA and the OPC respectively. Both instruments were calibrated before the field campaign by using known concentrations of mono-disperse ammonium sulphate aerosols and PSL aerosols.

20 Aerosol samples were also collected on filters within two size fractions (fine mode with particle diameters smaller than $2 \mu \mathrm{m}$ and coarse mode with particle diameters larger than $2 \mu \mathrm{m}$ ) before, during and after the fog event. Aerosol mass concentration was determined by gravimetric measurements and chemical analysis of the major components (ions, carbon, metals) were performed for these two size fractions using the procedure reported by Sciare et al. (2005).

The fog droplet number size distribution was measured using another OPC (model Pallas Welas 2000) especially designed for environmental monitoring. The optical sensing volume was set-up outdoors at a height of about $2 \mathrm{~m}$ and connected to the 17973

rest of the device via an optical fibre. The Pallas Welas OPC was regularly calibrated using mono-disperse polystyrene latex (PSL) aerosols. The calibration curve was corrected to take the refractive index of water into account. The droplet number distribution was measured within a diameter range of $0.4-40 \mu \mathrm{m}$.

\section{3.3 The intensive observation period 13: 18-19 February 2007}

\subsubsection{Synoptic situation}

During this IOP, the Paris region was in a ridge of high pressure. The atmosphere cooled rapidly between $15: 00$ and 23:00 UTC $\left(-2 \mathrm{Kh}^{-1}\right.$ on average at $2 \mathrm{~m}$, Fig. 1a). The fog appeared over the site at around 22:30 UTC (horizontal visibility less than $101000 \mathrm{~m}$ ) and became dense (horizontal visibility less than $70 \mathrm{~m}$ ) after 23:00 UTC (Fig. 1b). The vertical radiosounding carried out at 03:00 UTC suggests a rapid vertical development of fog with an observed height of $130 \mathrm{~m}$, characterized by a welldeveloped mixed layer within the fog layer. After 23:00 UTC, the temperature at $2 \mathrm{~m}$ remained around $268 \mathrm{~K}$ (Fig. 1a) until sunrise. The visibility remained below $150 \mathrm{~m}$

15 during the whole fog event (Fig. 1b). The dissipation of the fog layer occurred around 08:00 UTC (Fig. 1b).

\subsubsection{Aerosol properties}

The number concentration of aerosol particles measured by the integration of the SMPS data for a diameter between 10 and $500 \mathrm{~nm}$ is presented in Fig. 2. During 20 the period studied, the total number concentration of particles (solid line) varied between 5000 (at 12:00 UTC) and $20000 \mathrm{~cm}^{-3}$ just before the onset of the fog episode. Log-normal functions were fitted to the observed size distributions according to Eq. 3 to provide the modal parameters (i.e. amplitude, median diameter and standard deviation) of the various populations constituting the aerosol population before fog (Table 1). 
The fitted size distribution brings out the presence of two distinct modes of submicron particles: an Aitken mode $\left(D_{p}<50 \mathrm{~nm}\right)$ and an accumulation mode $\left(D_{p}>50 \mathrm{~nm}\right)$, typical of an urban aerosol. A preliminary analysis of these observations showed that the aerosol properties during IOP 13 were highly influenced by anthropogenic emissions,

5 with the presence of ultra fine particles (UFP) smaller than $100 \mathrm{~nm}$ (Fig. 2). These particles came from local sources and were either directly emitted from combustion sources (mainly from vehicles) or formed by chemical reactions resulting in gas-toparticle conversion. These processes are generally followed by a growth of particles by condensation, mostly from volatile organic compound (VOC) oxidation products (Se-

10 infeld and Pandis, 1998). These processes, along with the decreases of the boundary layer thickness, can explain the high aerosol number concentrations observed between 18:00 UTC and 00:00 UTC. The influence of coarse particles (like sea-salt or mineral dust) did not appear significant, as confirmed by measurements carried out with the Grimm OPC for the fraction of particles larger than $500 \mathrm{~nm}$ (not shown).

15 Table 1 also shows that the characteristics of the aerosol accumulation mode changed rapidly. At the beginning of the night, during strong radiative cooling; the median diameter increased from $78.5 \mathrm{~nm}$ at 17:00 UTC to $110 \mathrm{~nm}$ at 21:00 UTC. During this period, the aerosol number concentration increased rapidly from $7400 \mathrm{~cm}^{-3}$ to $11400 \mathrm{~cm}^{-3}$ between 17:00 UTC and 18:00 UTC, then after 19:00 UTC decreased to

$208300 \mathrm{~cm}^{-3}$. Since the aerosol size distribution was measured for a constant value of $\mathrm{RH}(<50 \%)$, the increase of median diameter can be attributed to the condensational growth of particles.

The analysis of aerosol chemical composition was based on filter samples collected between 20:00 UTC (18 February 2006) and 09:00 UTC (19 February 2006). Consequently, only an average mass of chemical compounds was determined, indicating that the overall aerosol composition was dominated by organic carbon (38.6\%) including Secondary Organic Aerosols (SOA) and Primary Organic Aerosol (POA). Unfortunately, the measurement system was not able to separate SOA from POA in the observed total organic mass. The total particulate organic matter (POM) was estimated

17975

to be $[P O M]=1.6[O C]$ (Putaud et al., 2000). The inorganic salts (ammonium sulphate and ammonium nitrate) were derived from the chemical analysis, which measured the mass of sulphates, nitrates and ammonium. The inorganic aerosol fraction mass was also large, with $25 \%$ of ammonium sulphate and $20 \%$ of ammonium nitrate. Soot (BC) 5 formed $16.4 \%$ of the total mass. This chemical mass composition of aerosol indicates that aerosol particles observed during the period of interest were rather hydrophilic.

The aerosol characteristics (chemical composition and size distribution obtained for the two fitted modes) observed at 21:00 UTC and described above, were taken for the initialization of the so-called "reference" numerical simulation in Sects. 4 and 5.

10 The size distribution of the two modes corresponds to median diameters of $33 \mathrm{~nm}$ and $110 \mathrm{~nm}$ and standard deviations of 1.57 and 1.59 for the Aitken and the accumulation modes respectively.

\section{Sensitivity of activation to aerosol properties}

This section focuses on the sensitivity of CCN activation to aerosol properties, such as the aerosol number concentration, the aerosol size distribution and their chemical composition. In order to isolate the sensitivity of activation processes, all the other physical processes were ignored. In these so-called "off-line" simulations, the atmospheric conditions and the aerosol characteristics were imposed, and only the activation module was used. All the numerical simulations presented here had stationary atmospheric 20 conditions typical of fog during winter $(278 \mathrm{~K}$ for temperature, $995 \mathrm{hPa}$ for pressure and $100 \%$ relative humidity). The sensitivity of CCN activation was studied for different air masses encountered above continental surface. The physical and chemical properties of the aerosols studied are summarized in Table 2. The reference case corresponds to the observed aerosol discussed in the previous section. The sensitivity of CCN activa-

25 tion to aerosol number concentration, aerosol size and aerosol chemical composition were studied independently. This allowed us to determine the most sensitive aerosol characteristics. In a first step, we studied the effect of aerosol number concentration for 
the aerosol size distribution and the chemical composition corresponding to the reference case. In the second step, the effect of the aerosol median diameter was studied for fixed chemical composition and three aerosol number concentrations corresponding to clean, rural and polluted areas. Finally, the effect of chemical composition was

5 studied for different aerosol sizes. The aerosol density $\rho_{a p}$ was set to $1.8 \mathrm{~g} \mathrm{~cm}^{-3}$ and the osmotic coefficient $\phi$ was taken equal to 1 for all chemical compounds following Mircea et al. (2002). Sensitivity studies were restricted to the accumulation mode in this section because activated aerosols in the Aitken mode were negligible due to their small size.

\section{$10 \quad 4.1$ Sensitivity tests on aerosol concentration}

The sensitivity tests presented here focused on the impact of aerosol concentration on the CCN activation. Different cases were considered according to the cooling rate. The studied aerosol concentrations were representative of polluted urban areas where aerosols are freshly emitted to a plume spreading from polluted urban areas to rural

15 or clean areas. In the latter case, the air mass becomes diluted during the transport, leading to a decrease in the aerosol number concentration. We assumed that the aerosol chemical composition and size distribution did not change with dilution and remained equal to the reference case (median diameter of $110 \mathrm{~nm}$, geometric standard deviation of 1.59 and the reference chemical composition given in Table 3).

20 Figure $3 a$ shows the activated aerosol fraction as function of aerosol number concentration for a cooling rate of $-10 \mathrm{Kh}^{-1}$. Three environments can be distinguished according to aerosol number concentration. For the first environment, corresponding to a polluted area $\left(\mathrm{N}_{a}>8000\right.$ particle $\left.\mathrm{cm}^{-3}\right)$ as observed during IOP 13 , the activated aerosol fraction is very small (less than $5 \%$ ). The second environment corresponds 25 to a rural area $\left(100<\mathrm{N}_{a}<8000\right.$ particle $\left.\mathrm{cm}^{-3}\right)$, where the fraction of activated aerosol increases linearly with the aerosol number concentration. The third environment is a clean environment $\left(\mathrm{N}_{a}<100\right.$ particle $\left.\mathrm{cm}^{-3}\right)$ in which more than $75 \%$ of particles are activated. When aerosol concentration increases, the maximum supersaturation $\mathrm{S}_{\max }$ 17977

decreases, and the critical diameter to activate aerosols increases. Consequently, the activated fraction decreases with an increase of aerosol concentrations. However, it should be pointed out that, due to the large number of aerosols in the polluted case, the number of activated aerosols will be greater than for the clean case.

The influence of cooling rates in contrasting environments are further investigated here. To represent these three environments, we considered a clean area with 83 particle $\mathrm{cm}^{-3}$, a rural area with 830 particle $\mathrm{cm}^{-3}$ and a polluted area with 8300 particles $\mathrm{cm}^{-3}$. The cooling rates imposed were representative of the cooling rate observed near the ground during fog formation (cooling rate by $0 \mathrm{Kh}^{-1}$ to $-4 \mathrm{Kh}^{-1}$ )

10 and that found at the top of the fog layer during the development phase (cooling rate by $-4 \mathrm{Kh}^{-1}$ to $-15 \mathrm{Kh}^{-1}$ ), e.g. Brown and Roach (1976); Bergot and Guedalia (1994). For the three environments described previously, the fraction of activated aerosol increased with the cooling rate (Fig. $3 b$ ). However, it increased more rapidly for the clean case than for a polluted one. For a cooling rate of $-2 \mathrm{Kh}^{-1}$, the fraction activated was

15 insignificant for a polluted area, was $10 \%$ for a rural area and $40 \%$ for a clean area. For a cooling rate of $-10 \mathrm{~K} \mathrm{~h}^{-1}$, the fraction activated was $4 \%$ for a polluted area, $40 \%$ for a rural area and $80 \%$ for a clean area. Whatever the aerosol number concentration, the number of activated aerosols (i.e. cloud droplets) was higher during the development phase (at the top of the fog), when the cooling rate became stronger than during the

20 fog formation (at the ground). The cooling rate is a crucial factor, which changes during the life cycle of fog and acts directly on the number of cloud droplets. In a fog layer, the cooling rate depends strongly on the divergence of the radiative fluxes, which depends on the liquid water content (LWC) and, consequently on the microphysical properties of the fog layer. This point will be studied in Sect. 5 .

254.2 Sensitivity tests on the aerosol median diameter

The sensitivity tests presented here focus on the impact of the median diameter of the aerosol distribution on CCN activation. The aerosol chemical composition and the shape of the size distribution correspond to the reference case and the cooling rate 
is imposed at $-10 \mathrm{Kh}^{-1}$. Figure $4 \mathrm{a}$ and Fig. $4 \mathrm{~b}$ show the number of activated CCN and the maximum supersaturation respectively for the three environments defined previously (urban polluted, rural and clean areas) as a function of aerosol particle median diameter. It can be seen from Fig. $4 a$ that, in a clean area, all aerosols having a me5 dian diameter greater than $120 \mathrm{~nm}$ are activated into cloud droplets. But the activated number stays smaller in the clean area than in rural or polluted areas whatever the aerosol size. In the case of small aerosol number concentration (i.e. clean area), the maximum supersaturation reached by the air mass is high (more than $0.2 \%$, Fig. $4 \mathrm{~b}$ ). For polluted and rural areas, two behaviours can be distinguished in Fig. 4a according

10 to the aerosol median diameter. Firstly, for a median diameter of less than $100 \mathrm{~nm}$, the number of activated CCN is higher in a polluted area than in a rural one. The maximum supersaturation decreases with the aerosol median diameter (Fig. 4b). Secondly, for a median diameter bigger than $100 \mathrm{~nm}$ in the case under study, the number of activated aerosols is higher in the rural area than in urban polluted areas. For a high aerosol 15 number concentration, the available water is distributed among all the aerosols and each aerosol takes a smaller amount of water in polluted areas than in rural ones. In the urban polluted area, more big aerosols are preferentially activated preventing the maximum supersaturation of the air mass from increasing. Thus, the number of activated aerosols decreases. On the contrary, in rural areas, fewer big aerosols are 20 activated, the maximum supersaturation can become greater and higher proportion of the aerosol spectrum can be activated. The characteristics of the aerosol size distribution act on the maximum supersaturation and on the activation process. For example, for an aerosol mean diameter of $200 \mathrm{~nm}, 80$ cloud droplets per $\mathrm{cm}^{3}$ are formed for a clean area $\left(S_{\max }=0.3 \%\right)$ whereas there are 500 cloud droplets per $\mathrm{cm}^{3}$ for a rural area $25 \quad\left(S_{\max }=0.1 \%\right)$ and 400 cloud droplets per $\mathrm{cm}^{3}$ for a polluted area $\left(S_{\max }=0.03 \%\right)$.

17979

\subsection{Sensitivity tests on the aerosol chemical composition}

The sensitivity tests presented here focus on the impact of the aerosol chemical composition on $\mathrm{CCN}$ activation. The aerosol concentration and the size distribution correspond to the reference case and the cooling rate imposed is $-10 \mathrm{Kh}^{-1}$. Numerical

5 computations were performed for six aerosol chemical compositions representative of different environments as detailed in Table 3. Following the study of Saxena et al. (1995), atmospheric organics are differentiated in terms of their interactions with water, into: a hydrophobic function having a surfactant behaviour (represented in our study by SOA8 hydrophobic type) and a hydrophilic function (represented by SOA1 hydrophilic

10 type) which is condensable and water soluble, therefore behaving like inorganic compounds.

Figure $5 \mathrm{a}$ shows the activated aerosol fraction and number and Fig. $5 \mathrm{~b}$ the maximum supersaturation as a function of aerosol median diameter for the six aerosol chemical compositions. As previously shown for the reference case, the fraction activated in-

15 creases with the aerosol median diameter for all the chemical compositions studied (Fig. 5a). Considering chemical compositions corresponding to near combustion (NC with $5 \%$ of soluble material), dust (with $10 \%$ of soluble material), and marine (completely soluble) as described in Table 3, the fraction activated increases mainly due to the salt fraction (Raoult effect). Sulphates (marine cases) activate more easily than

20 dust and NC because the sulphate particle mass is entirely dissociated in the aqueous phase while only $10 \%$ of dust particle mass and $5 \%$ of $\mathrm{NC}$ are considered soluble here. These three compositions do not affect the surface tension, which is $75.2 \mathrm{dyn} \mathrm{cm}^{-1}$. This value corresponds to the surface tension of pure water. From a median diameter larger than $150 \mathrm{~nm}$, the aerosol number activated is $420 \mathrm{~cm}^{3}$ for the marine case. The

25 effect of sulphates becomes insignificant for large aerosol sizes and only $4.8 \%$ of the spectrum is activated.

Looking at the effect of surfactants (represented by the reference case, Reference_SOA1 and Reference_SOA8 compositions) on surface tension (at aerosol median 
diameter of $110 \mathrm{~nm}$ ), the results show that organic compounds reduce surface tension from $\tau=75 \mathrm{dyn} \mathrm{cm}^{-1}$ (Reference IOP 13), to $\tau=74.5 \mathrm{dyn} \mathrm{cm}^{-1}$ (Reference_SOA8) and to $\tau=70.7 \mathrm{dyn} \mathrm{cm}^{-1}$ (Reference_SOA1). This effect reduces the particle critical supersaturation $\left(S_{m}\right)$ and thus increases the fraction activated. Organic compounds SOA1,

5 SOA8 and POM contained in aerosols have a different impact on particle activation. Only the difference between the compounds SOA1 and SOA8 will be discussed here. Unlike the SOA1 compound, which is soluble, the SOA8 compound acts only on the Kelvin effect because it is undissolved matter. As a result, the interaction of SOA1 and SOA8 with water is totally different. As mentioned previously, the chemical composition

10 with SOA1 has a more important impact on surface tension than the one associated with the SOA8 compound. Moreover, the SOA1 compound absorbs more water than SOA8, increasing the salt fraction (SOA1 is dissociated), thus adding an amount of additional water absorbed by inorganic salts which are also included in the aerosol composition (see Table 3). Consequently, the Reference_SOA1 composition leads to a 15 larger fraction of activated particles than Reference_SOA8 and Reference cases.

\subsection{Summary of off-line simulations}

These sensitivity tests are summarized in Table 4 and in Fig. 6. This study highlights the role of the atmospheric cooling rate and aerosol properties such as their number concentration, size distribution and chemical composition, on $\mathrm{CCN}$ activation. The magnitude of the cooling rate is a key factor in the aerosol activation process. Moreover, the aerosol number concentration is a strong driver of the activation process. The aerosol number influences the supersaturation of the atmosphere and thus the CCN activation. It is an important factor to be considered as shown in Fig. 6, where the number of cloud droplets formed is plotted against aerosol number concentration for 25 two contrasting cooling rates, $-2 \mathrm{Kh}^{-1}$ (solid line) and $-10 \mathrm{Kh}^{-1}$ (dashed line). Two behaviours can be observed on the number of aerosols activated according to aerosol number concentration. Firstly, for an aerosol number concentration less than a critical value, mainly depending on the cooling rate, the cloud droplet concentration increases 17981

when the aerosol number increases. The maximum activation rate occurs at this critical value. Secondly, if the aerosol concentration exceeds the critical value, then the number of activated $\mathrm{CCN}$ decreases when aerosol number increases. If aerosols become too numerous in the air parcel and reach this critical value (varying according to the

5 cooling rate considered), aerosols absorb a large quantity of water vapour, significantly decreasing the supersaturation within the air mass. This behaviour is found whatever the cooling rate. Frank et al. (1998) and Kokkola et al. (2003) studied fogs from observations made in the Po Valley, a rather polluted region of Italy. They characterized these types of events as "unactivated fogs".

10 Finally, aerosol chemical composition also influences the activation process. The water-soluble properties of compounds and the presence of organics compounds determine the ability of aerosols to capture water during the hygroscopic growth phase. This influences the supersaturation of the air mass and consequently the number of activated CCN.

\section{$15 \quad 5 \quad$ 1-D Numerical results}

Off-line simulations were an efficient way to isolate aerosol influences on the activation process for various environmental conditions often encountered in continental fog situations. However, to gain further insights, it is necessary to take into account the interactions among aerosols, and the microphysical and dynamic processes taking place

20 in the life cycle of fog. For example, the cooling rate varies strongly during the life cycle of fog: during the formation phase, cooling occurs near the ground and is relatively weak, while it is stronger and located near the top of the fog layer during the development phase. Consequently, the number of activated CCN should be greater during the development phase than during the initial phase. This topic is investigated in the 25 following section with 1-D simulations. 


\subsection{Model configuration}

The numerical simulations were initialized at 21:00 UTC on 18 February 2006. In this study, we will focus on the formation (before 00:00 UTC) and development phase (after 00:00 UTC) of the fog layer, and only the results of the night-time simulation will be 5 studied. The characteristics of the boundary layer (temperature, relative humidity, wind vertical profiles) at initial time were given by the 21:00 UTC radiosounding (Fig. 7). The soil type was determined from soil texture analysis and corresponded mainly to sandy loam. The surface cover was composed of $80 \%$ of temperate pastures, $15 \%$ of temperate sub-urban and $5 \%$ of lake surface-types. The initial vertical distribution of aerosol properties for all these simulations was set constant with height. The vertical grid spacing was set to $1 \mathrm{~m}$ and kept constant with height up to $50 \mathrm{~m}$. Such fine resolution is required to simulate a fog layer (Tardif, 2007). Above $50 \mathrm{~m}$, the vertical grid was gradually stretched.

\subsection{Validation of the reference simulation for intensive observation period 13: 18-19 February 2007}

For this reference simulation, the specified size distribution corresponded to the observed size distribution at 21:00 UTC. The aerosol total number concentration was initialized at 17000 aerosols per $\mathrm{cm}^{-3}$ with 8700 aerosols per $\mathrm{cm}^{-3}$ for the Aitken mode and 8300 aerosols per $\mathrm{cm}^{-3}$ for the accumulation mode as shown in Table 1. The

20 specified aerosol chemical composition corresponds to the observation at 21:00 UTC (see Sect. 3).

Figure 7 compares the observed and simulated vertical profiles of the potential temperature $\theta$ during the fog event at 21:00 UTC, 03:00 UTC and 06:00 UTC. The simulation underestimates $\theta$ by about $2 \mathrm{~K}$ inside the fog layer (i.e. below the thermal inversion). This difference is usual in 1-D simulations of fog. It can be explained by the idealized nature of the surface, which only roughly represents the actual heterogeneity of the site, and also by the limitation of 1-D simulations (e.g. the effect of horizontal

17983

advection is not taken into account). It is also worth noting that the thermal inversion is weaker and higher in the sounding than in the simulation at 03:00 UTC. The development of the fog layer is more rapid in the observation than in the simulation, leading to too cold a simulated fog layer. The height of fog is, however, well represented 5 at 06:00 UTC, even though the intensity of the thermal inversion is stronger than observed. It should be noted that the ascending velocity of the radiosonde $\left(10 \mathrm{~m} \mathrm{~s}^{-1}\right)$ which prevented an accurate estimation of the top of the fog layer.

The evolution of long-wave downward radiative flux at $2 \mathrm{~m}$ is illustrated in Fig. 8 . Before the formation of fog (before 23:00 UTC), the simulation seems to slightly underestimate the downward long-wave flux by $5 \mathrm{Wm}^{-2}$. However, this value is within the range of the measurement error. During the development phase, the long-wave downward flux is well-represented and reaches a value of $330 \mathrm{~W} \mathrm{~m}^{-2}$. Consequently, it seems that the liquid water content inside the fog layer is well simulated. In spite of the problems previously described, the model represents the formation and the devel15 opment of the fog layer relatively well.

Figure 9 represents the evolution of the observed and simulated cloud droplets number concentration at $2 \mathrm{~m}$. The formation phase is relatively well-simulated but the cloud droplet number concentrations are overestimated compared to measurements made during the development phase. The simulated maximum value is about 500 cloud 20 droplets $\mathrm{cm}^{-3}$ near the ground instead of the 250 cloud droplets $\mathrm{cm}^{-3}$ observed. The simulated values are also higher than values obtained during other field experiments like, for example, the Po Valley experiment, in which values of cloud droplets varied between 50 and 300 (Gultepe and Isaac, 1997; Wendish et al., 1998). This could be partially explained by the fact that the parameterization of Abdul-Razzak and Ghan

25 (2004) does not take kinetic limitations into account. Chuang et al. (1997) have shown that under certain circumstances growth kinetics may retard the growth of $\mathrm{CCN}$ sufficiently to limit the number of activated droplets formed. By comparing the time scale for particle growth at equilibrium with that for actual condensational growth, Chuang et al. (1997) conclude that particles with critical supersaturation less than a threshold value 
do not have time to grow larger than their critical size, and thus do not activate. This suggests that equilibrium models that diagnose droplet formation from maximum supersaturation may systematically overestimate the number of activated droplets formed (Nenes et al., 2001). Consequently, the maximum supersaturation and the number of 5 activated aerosols are slightly overestimated. Unfortunately, it is not possible to validate the diagnosed supersaturation again observations. It seems that it is difficult to measure the supersaturation in a fog layer because of the weak value and the localization (at the top of the fog layer). This could be the subject of future research. Moreover, rapid temporal fluctuations of cloud droplet number concentration are observed during

10 the development phase (Fig. 9). These fluctuations can be explained by complex interaction between microphysical and dynamic processes (e.g. gravity waves at the top of the fog layer leading to increased mixing) or by local modification of the physical properties of the air parcel (e.g. advection of more polluted aerosols from the Paris area). In the simplified 1-D simulation, it is not possible to take these processes into account.

The numerical results of the simulation for the cloud droplet number concentration are plotted in Fig. 10a. Fog formation takes place around 23:00 UTC, in good agreement with observations. At the beginning, the fog rises rapidly and then grows gradually to reach a height of $110 \mathrm{~m}$ at 03:00 UTC as mentioned before. The maximum number of cloud droplets is located at the top of the fog where the cooling rate is the greatest during the development phase. Figure 11 illustrates an example of a simulated vertical profile of the cooling rate at 03:00 UTC. The cooling rate is maximum near the top of the fog $\left(-9 \mathrm{Kh}^{-1}\right.$ for the reference case, thick solid line) and decreases rapidly to become very weak within the fog and close to zero at the ground. From 02:0003:00 UTC, the fog continues to develop vertically and the sedimentation process of cloud droplets becomes important (see accumulated precipitation for cloud droplets in Table 5). The liquid water path (LWP) diminishes slightly and the radiative cooling decreases (Table 5 for the so-called "polluted reference" case). As a result, the activation process becomes weaker during this development phase and the cloud droplet number concentration gradually decreases. Moreover, one can see in Fig. 10a that the

17985

cloud droplet concentration is relatively constant with height within the fog layer. This is explained by the turbulent mixing acting inside the fog layer. Consequently, the number of cloud droplets at the ground depends strongly on the history of the fog layer and on the number of cloud droplets formed at the top of the fog layer (sedimentation of fog 5 droplets).

For the case studied, the microphysical parameterization (Khairoutdinov and Kogan 2000 , microphysical scheme and the CCN activation parameterization of Abdul-Razzak and Ghan (2004)) used have realistic behaviour despite an overestimate of the cloud droplet number. The sensitivity of the life cycle of fog to aerosol type will now be stud-

10 ied. These sensitivity simulations differ in the specification of the aerosol concentration and aerosol chemical composition from the reference simulation described previously.

\subsection{Evolution of a fog layer with aerosol number concentration: a non-linear relation}

The previous section allowed us to validate the behaviour of the model for the refer15 ence case. In the following, numerical simulations results will be shown, with special emphasis on differences in microphysical structure of the fog layer. For the sensitivity experiments presented here, only the number concentration of the accumulation mode was changed. Three simulations were then performed using an aerosol concentration of 1000,5000 and 12000 particles per $\mathrm{cm}^{3}$ in the accumulation mode, varying from 20 the slightly polluted case to a heavily polluted case.

The evolution of the cloud droplet number concentrations is plotted in Fig. 10. Independently of the aerosol number concentration, fog forms approximately at the same time (around 23:00 UTC) which is due mainly to the thermodynamic conditions associated with the local air mass. But the vertical development and the characteristics 25 of the fog layer are significantly different. Table 5 details the evolution of the maximum height of the fog, the maximum cooling rate, the highest value of $S_{\max }$, the maximum cloud droplet number concentration, the LWP, the accumulated precipitation at the surface for the cloud droplets and the effective droplet radius for the four 
types of aerosol concentrations considered. At 06:00 UTC, the fog layer exhibits a greater vertical development in the case of 5000 particles $\mathrm{cm}^{-3}(180 \mathrm{~m}$, Fig. $10 \mathrm{c})$ and in the reference simulation $\left(170 \mathrm{~m}\right.$, Fig. 10a) than for the cases of $1000 \mathrm{~cm}^{-3}$ (150 metres, Figure 10b) and $12000 \mathrm{~cm}^{-3}(150 \mathrm{~m}$, Fig. 10d). However, the number of cloud

5 droplets varied during the life cycle of fog for the four cases studied. At 00:00 UTC, the cloud droplet number reached a value of 120 droplets per $\mathrm{cm}^{3}$ for the slightly polluted case $\left(1000 \mathrm{~cm}^{-3}\right), 400 \mathrm{~cm}^{-3}$ for the more polluted case $\left(5000 \mathrm{~cm}^{-3}\right), 380 \mathrm{~cm}^{-3}$ for the polluted case $\left(8300 \mathrm{~cm}^{-3}\right.$, reference) and only $220 \mathrm{~cm}^{-3}$ for the heavily polluted case (Table 5). At 06:00 UTC, the concentration was off by 35 droplets per $\mathrm{cm}^{3}$ for the 10 slightly polluted case $\left(1000 \mathrm{~cm}^{-3}\right), 200 \mathrm{~cm}^{-3}$ for the more polluted case $\left(5000 \mathrm{~cm}^{-3}\right)$, $100 \mathrm{~cm}^{-3}$ for the reference case $\left(8300 \mathrm{~cm}^{-3}\right)$ and $50 \mathrm{~cm}^{-3}$ for the heavily polluted case $\left(12000\right.$ particles $\left.\mathrm{cm}^{-3}\right)$. The number of aerosols strongly influences the supersaturation of the atmosphere and, in consequence, directly influences number of cloud droplets. As previously mentioned, the maximum activation rate is located at the top of 15 the fog where the radiative cooling is the strongest.

Figure 12 describes the LWC vertical profiles at 23:00, 00:00, 03:00 and 06:00 UTC for the four cases studied. Whatever the sensitivity simulations, liquid water is mostly condensed at the top of the fog layer where the cooling rate is the greatest (Fig. 11). However, LWC profiles depend strongly on the aerosol number concentration and con-

20 sequently on the droplet number concentration. The interactions between the droplet number concentration and the LWC are quite complex: an increase in LWC does not necessarily change the droplet number concentration. During the formation stage (23:00 UTC), the LWC is greatest $\left(0.2 \mathrm{~g} \mathrm{~kg}^{-1}\right)$ in the slightly polluted case compared to $0.1 \mathrm{~g} \mathrm{~kg}^{-1}$ for the reference case and only $0.07 \mathrm{~g} \mathrm{~kg}^{-1}$ for the most polluted case.

25 These values are in accordance with the study of Wendish et al. (1998). During the development phase, after 00:00 UTC, the behaviour is quite different. Feedback occurs between the radiative and microphysical processes. If the LWP increases (i.e. the LWC increases for a given height of fog), the radiative cooling at the top of the fog will also increase, promoting aerosol activation (Table 5). The LWC at the top of the fog layer is

17987

$0.41 \mathrm{~g} \mathrm{~kg}^{-1}$ for an aerosol concentration of $5000 \mathrm{~cm}^{-3}$ whereas it is only $0.15 \mathrm{~g} \mathrm{~kg}^{-1}$ in the most polluted case (concentration of 12000 particle $\mathrm{cm}^{-3}$ ). The LWC is influenced not only directly by the cooling rate but also indirectly by the aerosol number concentration. Thus, the aerosol number concentration seems to be an important factor to be 5 taken into account when the life cycle of fog is represented.

Figure 13 shows the evolution of the LWP during the simulation for the four cases studied. Two behaviours are apparent. Firstly, during the formation phase, the LWP is highest in the slightly polluted case $\left(5.8 \mathrm{~g} \mathrm{~m}^{-2}\right.$ at 23:00 UTC) compared with the other cases. The cooling rate is highest $\left(-8.5 \mathrm{Kh}^{-1}\right.$, see Table 5$)$ in the slightly polluted case.

10 Secondly, during the phase, from 02:00 UTC, the slightly polluted case produces the weakest LWP among all sensitivity simulations, whereas the case with 5000 aerosols per $\mathrm{cm}^{3}$ leads to the highest LWP $\left(46 \mathrm{~g} \mathrm{~m}^{-2}\right.$ at 06:00 UTC). This is explained by the difference of accumulated precipitation for the cloud droplets (Table 5) due to the difference of settling velocity of the fog droplets. The accumulated precipitation for rain is 15 negligible. The aerosol number concentration influences the cloud droplet concentration and size, which themselves affect the settling velocity and thus the accumulated precipitation at the ground. This affects the LWP and, indirectly, the height of the fog. Under very polluted conditions, the decrease of $S_{\max }$ leads to a reduction of the cloud droplet number concentration and consequently the droplet size becomes larger (increasein effective droplets radius, Table 5). The difference of LWC at the top of the fog layer among the cases studied affects the divergence of radiative fluxes at the top of the fog layer and thus the radiative cooling. This interaction between the microphysical and the radiative processes explain the reduction of the cloud droplet concentration during the development of fog. 


\subsection{Sensitivity of fog formation and development to aerosol chemical composition}

Two additional 1-D simulations were performed to study the impact of the aerosol chemical composition (with different solubilities) on the formation and the development of ra-

5 diative fog. To perform these sensitivity simulations, the chosen chemical composition corresponded to a mineral aerosol case (with $10 \%$ solubility) and to Reference_SOA1 (with $85 \%$ solubility) (see Table 3). The results of the numerical simulations are shown in Fig. 14, in which the evolution of the cloud droplet number concentration is plotted for the mineral aerosol case and the Reference_SOA1 case. The aerosol number concentrations were fixed at $8700 \mathrm{~cm}^{-3}$ and $8300 \mathrm{~cm}^{-3}$ for the Aitken and accumulation modes respectively.

The fog again forms approximately at the same time (23:00 UTC) for these three chemical compositions. As for the sensitivity to the aerosol number concentration, the aerosol chemical composition does not affect the time of fog formation. In contrast,

15 the cloud droplet number concentration is quite different during the fog event. For the $10 \%$ soluble case (referred to as the mineral aerosol case), at 06:00 UTC, the number of cloud droplets is $50 \mathrm{~cm}^{-3}$ lower at the ground and the height of fog only reaches $70 \mathrm{~m}$. In comparison, the $85 \%$ soluble case (named Reference_SOA 1 case) produces 600 cloud droplets $\mathrm{cm}^{-3}$ at the top of the fog layer, a value slightly higher than for the 20 Reference IOP 13 case (effect of surfactants, see Sect. 4.3).

Table 6 shows the evolution of the maximum height of fog, the maximum cooling rate, the highest value of $S_{\max }$, the maximum cloud droplet number concentration, the LWP, the accumulated precipitation and the effective droplets radius for the two aerosol chemical compositions considered. As for the aerosols number concentration, 25 the aerosol chemical composition strongly influences the LWC. During the formation phase, at 23:00 UTC, the height of the fog layer is the same for both cases. But during the development phase, between 00:00 and 03:00 UTC, the behaviour is quite different. In the Reference_SOA1 case, the height of fog increases more than in the mineral

17989

aerosol case, and the radiative cooling at the top of the fog also increases, $-18 \mathrm{Kh}^{-1}$ at 00:00 UTC, promoting aerosol activation and leading to a cloud droplet concentration of 1050 cloud droplets $\mathrm{cm}^{-3}$ at the top of the fog layer.

As for simulations of sensitivity to aerosol number concentration, the aerosol chemi5 cal composition influences the cloud droplet concentration and size, which themselves affect the settling velocity and thus the accumulated precipitation at the ground (Table 6). This indirectly affects the LWP and depth of the fog layer. Thus, the amount of condensed water is smaller at the top of the fog for the mineral aerosol case than for the Reference_SOA1 case. The maximum value of LWP is $8.8 \mathrm{~g} \mathrm{~m}^{-2}$ for mineral aerosols 10 whereas it reaches $44 \mathrm{~g} \mathrm{~m}^{-2}$ in the Reference_SOA1 case. The fog layer reaches a height of $180 \mathrm{~m}$ in the Reference_SOA1 case whereas it only reaches $70 \mathrm{~m}$ in the case of mineral aerosols at 06:00 UTC.

\section{Conclusions and recommendations}

This study evaluated the impact of aerosols (number concentration, size distribution 15 and chemical composition) during the formation and development stages of radiation fog. The particularity of fog in opposition to other boundary layer clouds is that the cooling rate (responsible of the $\mathrm{CCN}$ activation into cloud droplets) is related to the radiative cooling rather than the adiabatic cooling associated with updrafts. Fogs also form near the ground, where the variability of aerosol number concentration is the highest.

20 A simplified off-line framework allowed us to study the sensitivity of CCN activation to different key parameters such as the cooling rate, the aerosol number concentration, the aerosol size and its chemical composition. The results of these simulations underline the key role played by radiative cooling in the activation process. Radiative cooling is the main source of condensed water and aerosols, by their capabilities to act as CCN from the sink of water vapour. The cloud droplets formed in radiation fogs are the net budget of these two processes. It has been shown that water transfer to aerosols can limit the activation processes under polluted conditions. In the case, 
where aerosols are numerous, the maximum supersaturation reached within the air mass remains weak, preventing particles from reaching their critical activation diameter. For a fixed aerosol size distribution, it is possible to determine a critical value of aerosol number concentration, which primarily depends on the cooling rate. If the 5 aerosol number concentration is lower than this critical value, the number of activated $\mathrm{CCN}$ increases with the aerosol number. The maximum of activation rate is reached at this critical value. Afterwards, the number of CCN activated decreases when the aerosol number concentration increases.

Complementing the off-line sensitivity simulations, a radiation fog event (IOP 13 of

10 the ParisFOG field experiment) was studied in detail using results from 1-D simulations. Comprehensive simulations of this radiation fog event were performed using an online coupling of the Meso-NH meteorological model with the ORILAM aerosol scheme. This configuration takes account of the interactions between aerosol size distribution, their chemical properties and the microphysical and dynamic processes taking place

15 during the fog life cycle. Comparisons between a baseline simulation and observations show that the model can realistically simulate the event of interest. However, the cloud droplet number concentration is slightly overestimated. The parameterization of AbdulRazzak and Ghan (2004) does not take kinetic limitations into account. Growth kinetics may retard the growth of $\mathrm{CCN}$ sufficiently to limit the number of activated droplets 20 formed.

Sensitivity studies on the aerosol number concentration and chemical composition were then performed. It was found that the aerosol number concentration or chemical composition did not influence the time of fog formation for this case. But an impact on the microphysical properties and on the vertical development of fog was found. Under

25 polluted conditions, the aerosol number concentration limited the increase of maximum supersaturation of the air mass. This led to a greater number of larger cloud droplets and increased the deposition at the ground. In the strongly polluted case, the fraction of activated CCN decreased when the aerosol number increased and the amount of water created at the top of the fog was reduced. The decreased LWC led to a reduction

17991

of the radiative cooling at the top of the fog layer during the development phase. This interaction between the microphysical and the radiative processes also explains the reduction of the cloud droplet concentration. The development of dense fog is then limited under heavily polluted conditions, in which so called "unactivated fog" seems more

5 frequent. For these cases, it seems necessary to take the wet aerosol, and not only the cloud droplets, into account for the interactions with the other physical processes (e.g. visibility computation). These unactivated aerosols are also very important during the life cycle of fog, as they limit the activation processes.

The influence of aerosol characteristics on the dissipation phase has not be studied 10 and will be the subject of a future work. The particularity of the dissipation phase is the interaction between the fog microstructure and its interaction with shortwave radiation. Future research efforts will also take the interstitial aerosol characteristics into consideration along with their optical properties as a function of their chemical composition. The impact of these non-activated-aerosols on the dissipation of fog needs to 15 be studied.

In cases of strong pollution, the number of activated aerosols is less dependent on their chemical composition if their percentage of soluble material is sufficient. In the observed aerosol of ParisFOG, the aerosol mixture was composed of $55 \%$ of soluble inorganic material, $16.4 \%$ of soot and the $38.6 \%$ of organics. In this case, sensitiv-

20 ity studies on the type of organic matter (primary organic, hydrophobic or hydrophilic SOA) do not modify the fraction of activated aerosols by more than $10 \%$. Nevertheless, a stronger sensitivity appears where the aerosol matter is mostly composed of hydrophobic matter that is able to inhibit activation through the Raoult term. The amount of condensed water is then smaller at the top of the fog and the cloud droplet number 25 concentration decreases.

Another aspect which has not been addressed in this work is the effect of the cloud droplet number concentration on visibility computations. Gultepe et al. (2006) and Gultepe et al. (2007) show that the visibility predictions are directly based on the cloud droplet number concentration and the liquid water content depending on environmental 
conditions. The role of aerosol characteristics in determining visibility variations within fog layers should be clarified further in order to establish a comprehensive parameterization suitable for operational applications.

Acknowledgements. We would like to thank our colleagues at IPSL (Institut Pierre-Simon

5 Laplace), CEREA (Centre d'Enseignement et de Recherche en Environnement Atmosphérique) and CNRM/GAME/GMEI/4M for their collaboration and their contributions during the ParisFOG field experiment. We would also like to thank V. Masson, C. Lac for their assistance during the field modelisation and J. Sciare and P. Chazette for carrying out the aerosol chemical analysis. ParisFOG benefited from the funding of the Lefe programme by CNRS-Insu.

10

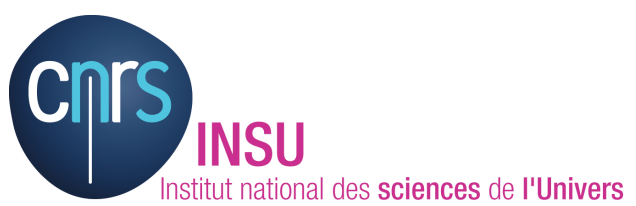

The publication of this article is financed by CNRS-INSU.

\section{References}

Abdul-Razzak, H. and Ghan, S.: A parameterization of aerosol activation 2, Multiple aerosol types, J. Geophys. Res., 105, 6837-6844, 2000. 17970

Abdul-Razzak, H. and Ghan, S.: Parameterization of the influence of organic surfactatnts on aerosol activation, J. Geophys. Res., 109, 1-11, 2004. 17964, 17967, 17970, 17972, 17984, 17986, 17991

Abdul-Razzak, H., Ghan, S., and Rivera-Carpio, C.: A parameterization of aerosol activation 1, Single aerosol type, J. Geophys. Res., 103, 6123-6131, 1998. 17966, 17970

Aikawa, M., Hiraki, T., Shoga, M., Tamaki, M., and Sumitomo, S.: Seven-year trend and the time and seasonal dependance of fog water collected near an industrialized area in Japan, Atmos. Res., 83, 1-9, 2007. 17966

17993

Badarinath, K., Madhavi Latha, K., Kiran Chand, T., Reddy, R., Rama Gopal, K., Siva Sankara Reddy, L., Narasimhulu, K., and Raghavendra Kumar, K.: Black carbon aerosols and gaseous pollutants in an urban area in North India during a fog episode, Atmos. Res., 85, 209-216, 2007. 17966

5 Bergot, T. and Guedalia, D.: Numerical forecasting of radiaton fog, Part1: Numerical model and sensitivity tests, Mon. Weather Rev., 122, 1218-1230, 1994. 17966, 17978

Bergot, T., Terradellas, E., Cuxart, J., Mira, A., Liechti, O., Muller, M., and Nielsen, N.: Intercomparison of single-column numerical models for the prediction of radiation fog, J. Appl. Meteorol. Clim., 46, 504-521, 2007. 17969

10 Bergot, T., Haeffelin, M., Musson-Genon, L., Colomb, M., Boitel, C., Bouhours, G., Bourriane, T., Carrer, D., Challet, J., Chazette, P., Drobinski, P., Dupont, E., Dupont, J., Elias, T., Fesquet, C., Garrouste, O., Gomes, L., Guerin, A., Lapouge, F., Lefranc, Y., Legain, D., Pietras, C., Plana-Fattori, A., Rangognio, J., Remy, S., Romand, B., and Zhand, X.: Paris-FOG: des chercheurs dans le brouillard, La Météorologie, 62, 48-58, 2008. 17967, 17972, 17973

15 Blando, J. D. and Turpin, B. J.: Secondary oragnic aerosol formation in cloud and fog droplets: a litterature evaluation of plausibility, Atmos. Environ., 34, 1623-1632, 2000. 17966

Bott, A.: On the influence of the physico-chemical properties of aerosols on the life cycle of radiative fogs, Bound.-Lay. Meteorol., 56, 1-31, 1991. 17966

Bott, A. and Carmichael, G.: Multiphase chemistry in a Microphysical radiation fog model - A numerical study, Atmos. Environ., 27A, 503-522, 1993. 17966

Bougeault, P. and Lacarrère, P.: Parameterization of Orography - Induced Turbulence in a Mesobeta-Scale Model, Mon. Weather Rev., 117, 1872-1890, 1989. 17968

Brown, R.: A numerical study of radiation fog with an explicit formulation of the microphysics, Q. J. Roy. Meteorol. Soc., 106, 781-802, 1980. 17966

25 Brown, R. and Roach, W.: The physics of radiation fog: II: a numerical study, Q. J. Roy. Meteorol. Soc., 102, 335-354, 1976. 17966, 17978

Cheng, C., Wang, W., and Chen, J.: A modelling study of aerosol impacts on cloud microphysics and radiative properties, Q. J. Roy. Meteorol. Society, 133, 283-297, 2007. 17966

Chuang, P., Charlson, R., and Seinfeld, J.: Kinetic limitations on droplet formation in clouds,

$30 \quad$ Nature, 393, 594-596, 1997. 17984

Cohard, J. and Pinty, J.: A comprehensive two-moment warm microphysical bulk scheme, I: Description and tests, Q. J. Roy. Meteorol. Soc., 126, 1815-1842, 2000a. 17966

Cohard, J. and Pinty, J.: A comprehensive two-moment warm microphysical bulk scheme, II: 
2-D experiments with a non hydrostatic model, Q. J. Roy. Meteorol. Soc., 126, 1843-1859, 2000b. 17966

Cuxart, J., Bougeault, P., and Redelsperger, J.-L.: A turbulence scheme allowing for mesoscale and large-eddy simulations, Q. J. Roy. Meteorol. Soc., 126, 1-30, 2000. 17968

5 Duynkerke, P.: Radiation fog: A comparison of model simulation with detailed observations, Mon. Weather Rev., 119, 324-341, 1991. 17966

Facchini, M., Decesari, S., Mircea, M., Fuzzi, S., and Loglio, G.: Surface tension of atmospheric wet aerosol and cloud/fog droplets in relation to their organic carbon content and chemical composition, Atmos. Res., 24, 4853-4857, 2000. 17966

10 Fisak, J., Tesar, M., Rezacova, D., Elias, V., Weignerova, V., and Fottova, D.: Pollutant concentrations in fog and low cloud water at selected sites of the Czech Republic, Atmos. Res., 64, 75-87, 2002. 17966

Fouquart, Y.: Radiative transfer in climate modeling, M. E. Schlesinger, 1987. 17968

Frank, G., Martinsson, B. G., Cederfelt, S., Berg, O. H., Swietlick, E., Wendisch, M., Yuskiewicz,

5 B., Heitzenberg, J., Wiedensohler, A., Orsini, A., Stratmann, F., Laj, P., and Ricci, L.: Droplet formation and growth in polluted fogs, Contr. Atmos. Phys., 71, 65-85, 1998. 17982

Geoffroy, O.: LES modeling of precipitation in boundary layer clouds and parameterization for general circulation model, Ph.D. thesis, Université Paul Sabatier, Toulouse, France, 2007. 17969

20 Ghan, S., Chuang, C., and Penner, J.: A parameterization of cloud droplet nucleation, part I, Single aerosol type, Atmos. Res., 30, 197-221, 1993. 17966

Griffin, R., Dabdub, D., and Seinfeld, J.: Secondary organic aerosol: 1, Atmospheric chemical mechanism for production of molecular constituents, J. Geophys. Res., 107, 4332, 2002. 17970

25 Griffin, R., Nguyen, K., Dabdub, D., and Seinfeld, J.: A coupled hydrophobic-hydrophilic model for predicting secondary organic aerosol formation, J. Atmos. Chem., 44, 171-190, 2003. 17970

Griffin, R., Dabdub, D., and Seinfeld, J.: Development and initial evaluation of a dynamic species-resolved model for gas phase chemistry and size-resolved gas/particle partitioning associated with secondary organic aerosol formation, J. Geophys. Res., 110, D05304, doi:10.1029/2004JD005219, 2005. 18001

Gultepe, I. and Isaac, G.: Scale effects on averaging of cloud droplet and aerosol number concentrations: Observations and models, J. Climate, 12, 1268-1279, 1997. 17984

17995

Gultepe, I., Muller, M., and Boybeyi, Z.: A new visibility parameterization for warm fog applications in numerical weather prediction models, J. Appl. Meteorol. Clim., 45, 1469-1480, 2006. 17992

Gultepe, I., Tardif, R., Michaelides, S. C., Cermak, J., Bott, A., Bendix, J., Muller, M. D., Pagowski, M., Hansen, B., Ellrod, G., Jacobs, W., Toth, G., and Cober, S. G.: Fog Research: A Review of Past Achievements and Future Perspectives, Pure Appl. Geophys., 164, 11211159, 2007. 17992

Husain, L., Khan, A., Ghauri, B., Dutkiewicz, V. A., and Farhana, B. K.: Carbonaceous and sulfate aerosols in highly polluted urban fog and clear air in South Asia, in: Fourth International

10 Conference on fog, fog collection and dew, La Serena, Chile, 2007. 17966

Kessler, E.: On the distribution and continuity of water substance in atmospheric circulation, Meteor. Mon., 32, 84 pp, 1969. 17969

Khairoutdinov, M. and Kogan, Y.: A new cloud parameterization in a Large-Eddy Simulation Model of Marine Stratocumulus, Mon. Weather Rev., 128, 229-243, 2000. 17967, 17969, 17986

Köhler, H.: The nucleus in and the growth of hygroscopic droplets, T. Faraday Soc., 32, 11521161, 1936. 17970

Kokkola, H., Romakkaniemi, S., and Laaksonen, A.: On the formation of radiation fogs under heavily polluted conditions, Atmos. Chem. Phys., 3, 581-589, 2003, http://www.atmos-chem-phys.net/3/581/2003/. 17982

Lafore, J. P., Stein, J., Asencio, N., Bougeault, P., Ducrocq, V., Duron, J., Fischer, C., Héreil, P., Mascart, P., Masson, V., Pinty, J. P., Redelsperger, J. L., Richard, E., and Vilà-Guerau de Arellano, J.: The Meso-NH Atmospheric Simulation System, Part I: adiabatic formulation and control simulations, Ann. Geophys., 16, 90-109, 1998,

25 http://www.ann-geophys.net/16/90/1998/. 17967, 17968

$\mathrm{Li}, \mathrm{Z}$., Willimans, A., and Rood, J. M.: Influence of Soluble Properties on the Activation of Aerosol Particles Containing Inorganic Solute, J. Atmos. Sci., 55, 1859-1866, 1998. 17966

Masson, V.: A physically-based scheme for the urban energy balance in atmospheric models, Bound.-Lay. Meteorol., 94, 357-397, 2000. 17969

30 Mircea, M., Facchini, M., Decesari, S., Fuzzi, S., and Charlson, R.: The influence of the organic aerosol component on CCN supersaturation spectra for different aerosol types, Tellus, 54B, 74-81, 2002. 17977

Mlawer, E., Taubman, S., Brown, M., lacono, M., and Clough, S.: Radiative transfer for inhomo- 
geneous atmospheres: RRTM, a validation correlated-k model for the longwave, J. Geophys. Res., 102D, 16662-16682, 1997. 17968

Moore, K. F., Eli Sherman, D., Reilly, J. E., Hannigan, M., Lee, T., and Collett Jr., J. L.: Drop size-dependent chemical composition of clouds and fogs, Part II: Relevance to interpreting the aerosol/trace gas/fog system, Atmos. Environ., 38, 1403-1415, 2004. 17966

Morcrette, J.-J.: Physical parametrization, ECMWF Forecast Model, ECMWF Tech. Memo. 165, 1989. 17968

Nakanishi, M.: Large-eddy simulation of radiation fog, Bound.-Lay. Meteorol., 94, 461-493, 2000. 17965

10 Nenes, A. and Seinfeld, J.: Parameterization of cloud droplet formation in global climate models, J. Geophys. Res., 108(D14), 4415, doi:10.1029/2002JD002 911, 2003. 17966

Nenes, A., Ghan, S., Abdul-Razzak, H., Chuang, Y., and Seinfeld, J.: Kinetic limitations on cloud droplet formation and impact on cloud albedo, Tellus, 53B, 133-149, 2001. 17985

Noilhan, J. and Planton, S.: A simple parameterization of land surface processes for meteorological models, Mon. Weather Rev., 117, 536-549, 1989. 17969

Pagowski, M., Gultepe, I., and King, P.: Analysis and modeling of an extremely dense fog event in southern Ontario, J. Appl. Meteorol., 43, 3-16, 2004. 17965

Pandis, S. and Seinfeld, J.: Mathematical modeling of acid deposition due to radiation fog, J. Geophys. Res., 94, 12911-12923, 1989a. 17966

20 Pandis, S. and Seinfeld, J.: Sensitivity analysis of a chemical mechanism for aqueous-phase atmospheric chemistry, J. Geophys. Res., 94, 1105-1126, 1989b. 17966

Press, W., Teukolsky, S., Vetterling, W., and Flannery, B. P.: Numerical recipes in FORTRAN: The art of scientific computing, 2nd Ed., Cambridge University Press, 1992. 17969

Pruppacher, H. and Klett, J.: Microphysics of Clouds and Precipitation, Kluwer Acad., Norwell, Mass, 1997. 17965

Putaud, J.-P., Van Dingenen, R., Mangoni, M., Virkkula, A., Raes, F., Maring, H., Prospero, J., Berg, O., Hillamo, R., and Makkela, T.: Chemical mass closure and assessment of the origin of the submicron aerosol in the marine boundary and the free troposphere at Tenerife during ACE2, Tellus, 52B(2), 141-168, 2000. 17976

30 Reilly, J. E., Rattigan, O., Moore, K., Judd, C., Eli Sherman, D., Dutkiewicz, V., Kreidenweis, S., Husain, L., and Collett Jr., J. L.: Drop size-dependant S(IV) oxidation in chemically heterogeneous radiation fogs, Atmos. Environ., 35, 5717-5728, 2001. 17966

Sandu, I., Brenguier, J., Geoffroy, O., Thouron, O., and Masson, V.: Aerosol impacts on the

17997

diurnal cycle of marine Stratocumulus, J. Atmos. Sci., 65, 2705-2718, 2008. 17969

Saxena, P. and Hildemann, L.: Water-soluble organics in atmosperic particles: a critical review of the literature and application of thermodynamics to identify candidate compounds, $\mathrm{J}$. Atmos. Chem., 24, 57-109, 1996. 17966

5 Saxena, P., Hildemann, L., McMurry, P., and Seinfeld, J. H.: Organics alter hygroscopic behavior of atmospheric particles, J. Geophys. Res., 100, 18755-18770, 1995. 17980

Sciare, J., Oikonomou, K., Cachier, H., Mihalopoulos, N., Andreae, M. O., Maenhaut, W., and Sarda-Estève, R.: Aerosol mass closure and reconstruction of the light scattering coefficient over the Eastern Mediterranean Sea during the MINOS campaign, Atmos. Chem. Phys., 5, 2253-2265, 2005,

http://www.atmos-chem-phys.net/5/2253/2005/. 17973

Seinfeld, J. and Pandis, S.: Atmospheric chemistry and physics, John Wiley, New-York, 1998. 17975

Seinfeld, J., Pandis, S., and Pilinis, C.: Heterogeneous sulfate production in an urban fog, Atmos. Environ., 26A, 2509-2522, 1992. 17966

Shulman, M., Jacobson, M., Carlson, R., Synovec, R., and Young, T.: Dissolution behavior and surface tension effects of organic compounds in nucleating cloud droplets, Geophys. Res. Lett., 23, 277-280, 1996. 17966, 17971

Smith, E. and Shi, L.: Surface forcing of the infrared cooling profile over the Tibetan plateau, Part I: Influence of relative longwave radiative heating at high altitude, J. Atmos. Sci., 49, 805-822, 1992. 17968

Tardif, R.: The impact of vertical resolution in the explicit numerical simulation of radiation fog : a case study, Pure Appl. Geophys., 164, 1221-1240, 2007. 17983

Tulet, P., Crassier, V., Cousin, F., Suhre, K., and Rosset, R.: ORILAM, a three-moment lognormal aerosol scheme for mesoscale atmospheric model: Online coupling into the Meso$\mathrm{NH}-\mathrm{C}$ model and validation on the Escompte campaign, J. Geophys. Res., 110, D18201-1D18201-13, 2005. 17967, 17969

Tulet, P., Grini, A., Griffin, J., and Petitcol, S.: ORILAM-SOA: A computationally efficient model for predicting secondary organic aerosols in three-dimensional atmospheric models, J. Geophys. Res., 111, D23208, doi:10.1029/2006JD007152, 2006. 17970, 18001

Twomey, S.: The nuclei of natural cloud formation, II, The supersaturation in natural clouds and the variation of cloud droplet concentration, Geophys. Pure Appl., 43, 243-249, 1959. 17966

Vautard, R., Yiou, P., and Oldenborgh, G. J. v.: Decline of fog, mist and haze in Europe over 
the past 30 years, Nat. Geosci., 2, 115-119, 2009. 17965

Wendish, M., Mertes, S., Heintzenberg, J., Wiedensohler, A., Schell, D., Wobrock, W., Frank, G., Martinsson, B., Fuzzi, S., Oris, G., Kos, G., and Berner, A.: Drop size distribution and LWC in Po Valley Fog, Contribution to Atmospheric Physics, 71/1, 87-100, 1998. 17984,

$5 \quad 17987$

Zappoli, S., Andracchio, A., Fuzzi, S., Facchini, M., Gelencser, A., Kiss, G., Krivacsy, Z., Molnar, A., Meszaros, E., Hansson, H.-C., Rosman, K., and Zebühr, Y.: Inorganic, organic and macromolecular components of fine aerosol in different areas of Europe in relation to their water solubility, Atmos. Environ., 33, 2733-2743, 1999. 17966

Table 1. IOP13, 18-19 February 2007: Aerosol size distribution characteristics measured from SMPS before the fog episode.

\begin{tabular}{lcccccc}
\hline $\begin{array}{l}\text { Time period } \\
\text { (UTC) }\end{array}$ & \multicolumn{3}{c}{$\begin{array}{c}\text { Aitken } \\
\text { Mode }\end{array}$} & & \multicolumn{3}{c}{$\begin{array}{c}\text { Accumulation } \\
\text { Mode }\end{array}$} \\
\hline & $\mathrm{N}\left(\mathrm{cm}^{-3}\right)$ & $\mathrm{D}_{p}(\mathrm{~nm})$ & $\sigma$ & $\mathrm{N}\left(\mathrm{cm}^{-3}\right)$ & $\mathrm{D}_{p}(\mathrm{~nm})$ & $\sigma$ \\
$17-18$ & 4050 & 17.4 & 1.51 & 7400 & 78.5 & 1.84 \\
$18-19$ & 5700 & 20.6 & 1.59 & 11400 & 81.2 & 1.87 \\
$19-20$ & 8200 & 30 & 1.64 & 10700 & 97.3 & 1.71 \\
$20-21$ & 7700 & 32 & 1.59 & 9700 & 102.0 & 1.68 \\
$21-22$ & 8700 & 33 & 1.57 & 8300 & 110 & 1.59 \\
\hline
\end{tabular}


Table 2. Physical and chemical properties of chemical compounds.

\begin{tabular}{lcccc}
\hline & $\begin{array}{c}\text { Compounds } \\
\text { Chemical }\end{array}$ & $\begin{array}{c}\text { Molecular } \\
\text { Weight }\end{array}$ & Solubility & $\begin{array}{c}\text { No. of } \\
\text { lons }\end{array}$ \\
\hline INORGANIC & $\begin{array}{c}\left(\mathrm{NH}_{4}\right)_{2} \mathrm{SO}_{4} \\
\mathrm{NH}_{4} \mathrm{NO}_{3}\end{array}$ & $\begin{array}{c}132 \\
80\end{array}$ & 1 & 3 \\
\hline INSOLUBLE & $\mathrm{SOOT}$ & 250 & 0 & 0 \\
\hline $\begin{array}{l}\text { ORGANIC } \\
\text { PRIMARY }\end{array}$ & $\mathrm{POM}$ & 250 & 0.1 & 1 \\
\hline MINERAL & DUST & 250 & 0.1 & 1 \\
\hline (AEROSOL) & & 88 & 0.99 & 1 \\
\hline ORGANIC & SOA1 & & & \\
SECONDARY & SOA8 $^{\mathrm{b}}$ & 195 & 0.23 & 0 \\
\hline
\end{tabular}

${ }^{*}$ SOA groups considered by Griffin et al. (2005) and by Tulet et al. (2006)

a SOA1 Hydrophilic Secondary Organic Aerosol (Anthropogenic, dissociative type)

${ }^{b}$ SOA8 Hydrophobic Secondary Organic Aerosol (Anthropogenic, poly-aromate type)

Table 3. The six aerosol chemical compositions used in the sensitivity tests in "off-line" simulations. The percentage represents the mass fraction of each compound contained in the aerosol.

\begin{tabular}{lccccccc}
\hline $\begin{array}{l}\text { Chemical } \\
\text { Composition }\end{array}$ & $\left(\mathrm{NH}_{4}\right)_{2} \mathrm{SO}_{4}$ & $\mathrm{NH}_{4} \mathrm{NO}_{3}$ & SOOT & POM & SOA1 & SOA8 & DUST \\
\hline $\begin{array}{l}\text { Near } \\
\text { Combustion }\end{array}$ & - & - & $50 \%$ & $50 \%$ & - & - & - \\
$\begin{array}{l}\text { Exhaust } \\
\text { Mineral Aerosol }\end{array}$ & - & - & - & - & - & - & $100 \%$ \\
$\begin{array}{l}\text { ParisFOG } \\
\text { Reference }\end{array}$ & $25 \%$ & $20 \%$ & $16.4 \%$ & $38.6 \%$ & - & - & - \\
IOP 13 & $100 \%$ & - & - & - & - & - & - \\
Marine & $25 \%$ & $20 \%$ & $16.4 \%$ & - & $38.6 \%$ & - & - \\
Reference_SOA1 & $25 \%$ & $20 \%$ & $16.4 \%$ & - & - & $38.6 \%$ & - \\
Reference_SOA8 & $20 \%$ & & & & & & - \\
\hline
\end{tabular}


Table 4. Summary of the sensitivity tests of cooling rate, aerosol chemical composition and geometric median diameter on the formation of fog droplets. The geometric standard deviation and the aerosol number concentration are 1.59 and 8300 particle $\mathrm{cm}^{-3}$ respectively. Percentages represent the fraction of activated aerosol. Numbers in parentheses represent the number of activated aerosols formed.

\begin{tabular}{|c|c|c|c|c|c|c|}
\hline & \multicolumn{6}{|c|}{ FORMATION (Cooling rate $=-2 \mathrm{Kh}^{-1}$ on the surface) } \\
\hline & $\begin{array}{c}\text { Near } \\
\text { Combustion }^{\mathrm{a}}\end{array}$ & $\begin{array}{l}\text { Mineral } \\
\text { Aerosol }\end{array}$ & $\begin{array}{l}\text { Reference } \\
\text { IOP } 13\end{array}$ & Marine & $\begin{array}{l}\text { Reference } \\
\text { SOA } 1^{\mathrm{b}}\end{array}$ & $\begin{array}{c}\text { Reference } \\
\text { SOA8 }\end{array}$ \\
\hline Diameter $40 \mathrm{~nm}$ & $\begin{array}{l}0 \% \\
(0)\end{array}$ & $\begin{array}{l}0 \% \\
(0)\end{array}$ & $\begin{array}{l}0.02 \% \\
(2)\end{array}$ & $\begin{array}{c}0.02 \% \\
(2)\end{array}$ & $\begin{array}{c}0.02 \% \\
\text { (2) }\end{array}$ & $\begin{array}{c}0.02 \% \\
(2)\end{array}$ \\
\hline Diameter $110 \mathrm{~nm}^{*}$ & $\begin{array}{l}0.01 \% \\
\text { (1) }\end{array}$ & $\begin{array}{l}0.02 \% \\
(2)\end{array}$ & $\begin{array}{c}0.03 \% \\
(3)\end{array}$ & $\begin{array}{c}0.036 \% \\
\text { (3) }\end{array}$ & $\begin{array}{c}0.046 \% \\
(4)\end{array}$ & $\begin{array}{c}0.037 \% \\
(3)\end{array}$ \\
\hline \multirow[t]{3}{*}{ Diameter $300 \mathrm{~nm}$} & $\begin{array}{l}0.03 \% \\
(3)\end{array}$ & $\begin{array}{c}0.035 \% \\
\text { (3) }\end{array}$ & $\begin{array}{l}0.04 \% \\
\text { (3) }\end{array}$ & $\begin{array}{c}0.037 \% \\
(3)\end{array}$ & $\begin{array}{c}0.048 \% \\
(4)\end{array}$ & $\begin{array}{l}0.04 \% \\
(3)\end{array}$ \\
\hline & \multicolumn{6}{|c|}{ DEVELOPMENT (Cooling rate $=-10 \mathrm{Kh}^{-1}$ at the top of the fog) } \\
\hline & $\begin{array}{c}\text { Near } \\
\text { Combustion }^{\mathrm{a}}\end{array}$ & Dust & Reference & Marine & $\begin{array}{l}\text { Reference } \\
\text { SOA } 1^{\mathrm{b}}\end{array}$ & $\begin{array}{c}\text { Reference } \\
\text { SOA8 }\end{array}$ \\
\hline Diameter $40 \mathrm{~nm}$ & $\begin{array}{l}0 \% \\
(0)\end{array}$ & $\begin{array}{l}0.01 \% \\
(1)\end{array}$ & $\begin{array}{l}1.5 \% \\
(121)\end{array}$ & $\begin{array}{c}2 \% \\
(167)\end{array}$ & $\begin{array}{l}1.8 \% \\
(147)\end{array}$ & $\begin{array}{l}1.4 \% \\
(122)\end{array}$ \\
\hline Diameter $110 \mathrm{~nm}^{*}$ & $\begin{array}{c}0.5 \% \\
(46)\end{array}$ & $\begin{array}{l}1 \% \\
(90)\end{array}$ & $\begin{array}{l}4.4 \% \\
(363)\end{array}$ & $\begin{array}{l}4.6 \% \\
(380)\end{array}$ & $\begin{array}{l}4.3 \% \\
(430)\end{array}$ & $\begin{array}{l}3.7 \% \\
(368)\end{array}$ \\
\hline Diameter $300 \mathrm{~nm}$ & $\begin{array}{l}3.5 \% \\
(295)\end{array}$ & $\begin{array}{c}4 \% \\
(339)\end{array}$ & $\begin{array}{l}5 \% \\
(421)\end{array}$ & $\begin{array}{l}5.1 \% \\
(421)\end{array}$ & $\begin{array}{l}5.8 \% \\
(483)\end{array}$ & $\begin{array}{l}5.1 \% \\
(426)\end{array}$ \\
\hline
\end{tabular}

${ }^{*}$ aerosol median diameter of the Reference Case IOP 13

${ }^{a}$ minimum cloud droplets number formed (minimum aerosol number activated)

${ }^{b}$ maximum cloud droplets number formed (maximum aerosol number activated)

Table 5. Numerical values of the maximum height of fog, the strongest cooling rate, the highest value of $S_{\max }$, the maximum cloud droplet concentration, the Liquid Water Path, the accumulated precipitation at the ground (for cloud droplets) and the effective droplets radius for the four sensitivity tests: slightly polluted (1000 aerosols per $\mathrm{cm}^{-3}$ ), more polluted (5000 aerosols per $\left.\mathrm{cm}^{-3}\right)$, polluted - reference $\left(8300\right.$ aerosols per $\mathrm{cm}^{-3}$ ) and heavily polluted (12000 aerosols per $\mathrm{cm}^{-3}$ ) at 23:00, 00:00, 03:00 and 06:00 UTC.

\begin{tabular}{ccccccccc}
\hline $\begin{array}{c}\text { Time of } \\
\begin{array}{c}\text { Simulation } \\
\text { (hours) }\end{array}\end{array}$ & $\begin{array}{c}\text { Sensitivity } \\
\text { tests }\end{array}$ & $\begin{array}{c}\text { Height } \\
\text { of fog } \\
\text { (meters) }\end{array}$ & $\begin{array}{c}\text { Cooling } \\
\text { rate } \\
\left(\mathrm{Kh}^{-1}\right)\end{array}$ & $\begin{array}{c}\mathrm{S}_{\max } \\
\%\end{array}$ & $\begin{array}{c}\text { Cloud } \\
\text { Droplets } \\
\text { Conc. }\left(\mathrm{cm}^{-3}\right)\end{array}$ & $\begin{array}{c}\text { Liquid Water } \\
\text { Path } \\
\left(\mathrm{g} \mathrm{m}^{-2}\right)\end{array}$ & $\begin{array}{c}\text { Accumulated } \\
\text { Precipitation } \\
(\mathrm{mm})\end{array}$ & $\begin{array}{c}\text { Effective } \\
\text { Droplets } \\
\text { Radius }(\mu \mathrm{m})\end{array}$ \\
\hline 23:00 UTC & Slightly Polluted & 30 & 8.5 & 0.15 & 160 & 5.8 & $9.5 \times 10^{-5}$ & 12 \\
& More Polluted & 30 & 8.3 & 0.082 & 320 & 4.6 & $4.9 \times 10^{-5}$ & 13 \\
& Polluted (Ref) & 30 & 7.6 & 0.057 & 180 & 3.4 & $6.1 \times 10^{-5}$ & 13 \\
& Heavily Polluted & 30 & 7.2 & 0.042 & 85 & 2.4 & $6.8 \times 10^{-5}$ & 14 \\
& Slightly Polluted & 50 & 11.5 & 0.175 & 203 & 13 & $1.6 \times 10^{-3}$ & 11 \\
00:00 UTC & More Polluted & 50 & 19.8 & 0.13 & 960 & 21 & $1.3 \times 10^{-3}$ & 12 \\
& Polluted (Ref) & 50 & 16.2 & 0.091 & 720 & 15 & $1.3 \times 10^{-3}$ & 12 \\
& Heavily Polluted & 50 & 12 & 0.060 & 310 & 7 & $1.3 \times 10^{-3}$ & 16 \\
& Slightly Polluted & 100 & 8.4 & 0.15 & 120 & 19 & $5.7 \times 10^{-3}$ & 11 \\
& More Polluted & 110 & 11 & 0.098 & 400 & 41 & $4.4 \times 10^{-3}$ & 8 \\
& Polluted (Ref) & 110 & 9 & 0.063 & 380 & 39 & $4.5 \times 10^{-3}$ & 8 \\
& Heavily Polluted & 100 & 8.6 & 0.048 & 220 & 30 & $4.6 \times 10^{-3}$ & 9 \\
& Slightly Polluted & 150 & 6.7 & 0.14 & 90 & 18 & $6.9 \times 10^{-3}$ & 13 \\
& More Polluted & 180 & 7 & 0.072 & 190 & 46 & $5.7 \times 10^{-3}$ & 10 \\
& Polluted (Ref) & 170 & 5 & 0.04 & 100 & 34 & $5.8 \times 10^{-3}$ & 12 \\
& Heavily Polluted & 150 & 3 & 0.022 & 35 & 19 & $6.1 \times 10^{-3}$ & 14 \\
\hline
\end{tabular}


Table 6. Same as Table 5 for the chemical sensitivity tests.

\begin{tabular}{|c|c|c|c|c|c|c|c|c|}
\hline $\begin{array}{c}\text { Time of } \\
\text { Simulation }\end{array}$ & $\begin{array}{l}\text { Sensitivity } \\
\text { tests }\end{array}$ & $\begin{array}{l}\text { Height } \\
\text { of fog }\end{array}$ & $\begin{array}{l}\text { Cooling } \\
\text { rate }\end{array}$ & $\underset{\%}{\mathrm{~S}_{\max }}$ & $\begin{array}{l}\text { Cloud } \\
\text { Droplets }\end{array}$ & $\begin{array}{l}\text { Liquid Water } \\
\text { Path }\end{array}$ & $\begin{array}{l}\text { Accumulated } \\
\text { Precipitation }\end{array}$ & $\begin{array}{l}\text { Effective } \\
\text { Droplets }\end{array}$ \\
\hline \multirow{2}{*}{ 23:00 UTC } & Mineral Aerosol & 30 & 6 & 0.16 & 30 & 1.6 & $8.1 \times 10^{-5}$ & 12 \\
\hline & Reference_SOA1 & 30 & 8 & 0.043 & 240 & 3.6 & $5.7 \times 10^{-5}$ & 14 \\
\hline \multirow{2}{*}{ 00:00 UTC } & Mineral Aerosol & 40 & 10 & 0.19 & 38 & 2.8 & $8.8 \times 10^{-3}$ & 15 \\
\hline & Reference_SOA1 & 50 & 18 & 0.074 & 1050 & 17 & $1.3 \times 10^{-3}$ & 9 \\
\hline \multirow{2}{*}{ 03:00 UTC } & Mineral Aerosol & 70 & 5 & 0.15 & 20 & 8.8 & $4.5 \times 10^{-3}$ & 17 \\
\hline & Reference_SOA1 & 110 & 11.8 & 0.056 & 460 & 44 & $4.3 \times 10^{-3}$ & 8 \\
\hline \multirow{2}{*}{ 06:00 UTC } & Mineral Aerosol & 70 & 2.5 & 0.10 & 15 & 8.5 & $7.9 \times 10^{-3}$ & 16 \\
\hline & Reference_SOA1 & 170 & 5.5 & 0.033 & 160 & 43 & $5.6 \times 10^{-3}$ & 8 \\
\hline
\end{tabular}

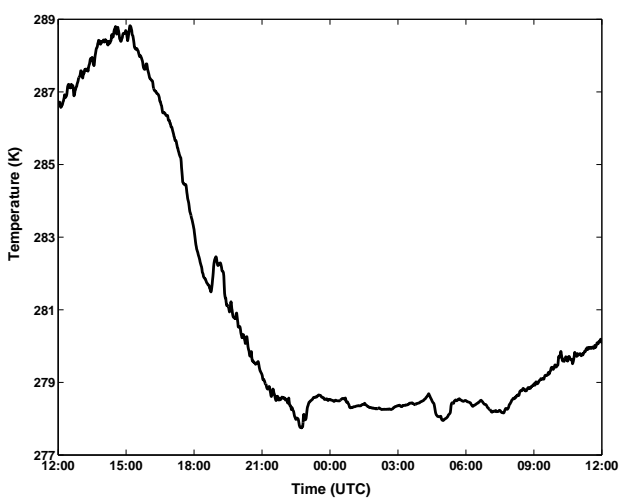

(a)

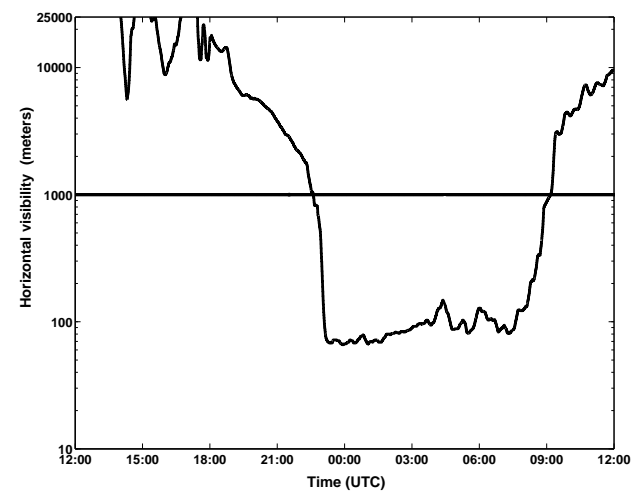

Fig. 1. IOP13, 18-19 February 2007: Evolution of the temperature (a) and the horizontal visibility (b) at $2 \mathrm{~m}$. 


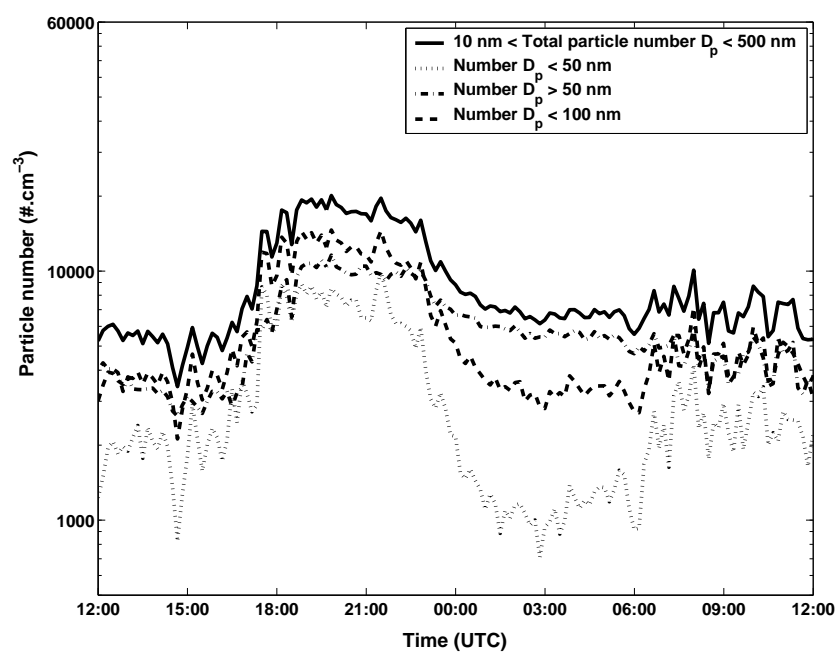

Fig. 2. IOP13, 18-19 February 2007: Evolution of the aerosol number concentration measured at $2 \mathrm{~m}$ by integration of the SMPS data between 10 and $500 \mathrm{~nm}$ (solid line), ranging from 10 to $50 \mathrm{~nm}$ (Aitken mode, dotted line), from 50 to $500 \mathrm{~nm}$ (Accumulation mode, dash-dot line) and from 10 to $100 \mathrm{~nm}$ (ultra-fine particles, dashed line).
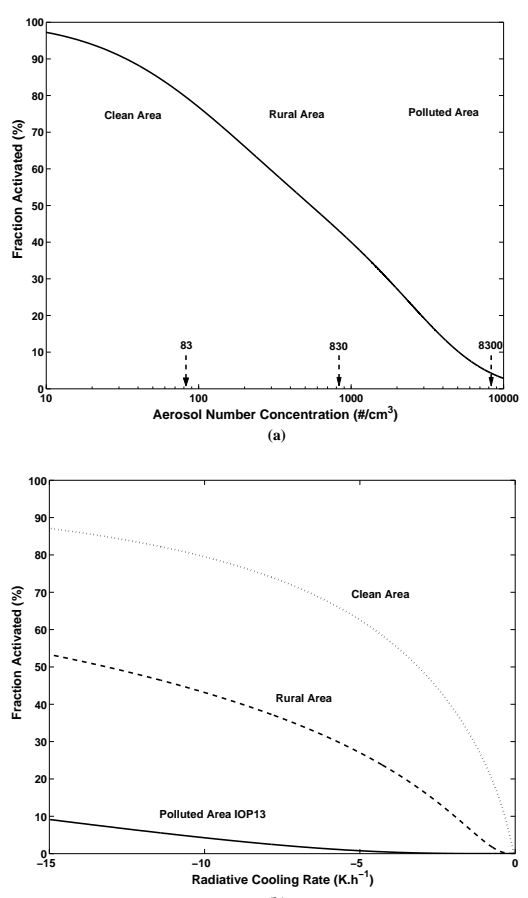

Fig. 3. (a) Fraction of activated aerosols as a function of aerosol number concentration for a cooling rate of $-10 \mathrm{Kh}^{-1}$. (b) Fraction of activated aerosols as function of the cooling rate for 3 types of aerosol number concentration: Polluted area with 8300 particles $\mathrm{cm}^{-3}$, Rural area with 830 particles $\mathrm{cm}^{-3}$ and Clean area with 83 particle $\mathrm{cm}^{-3}$. For (a) and (b), the aerosol median diameter is $110 \mathrm{~nm}$, the geometric standard deviation is 1.59 and the aerosol chemical composition is that of the Reference IOP 13. 

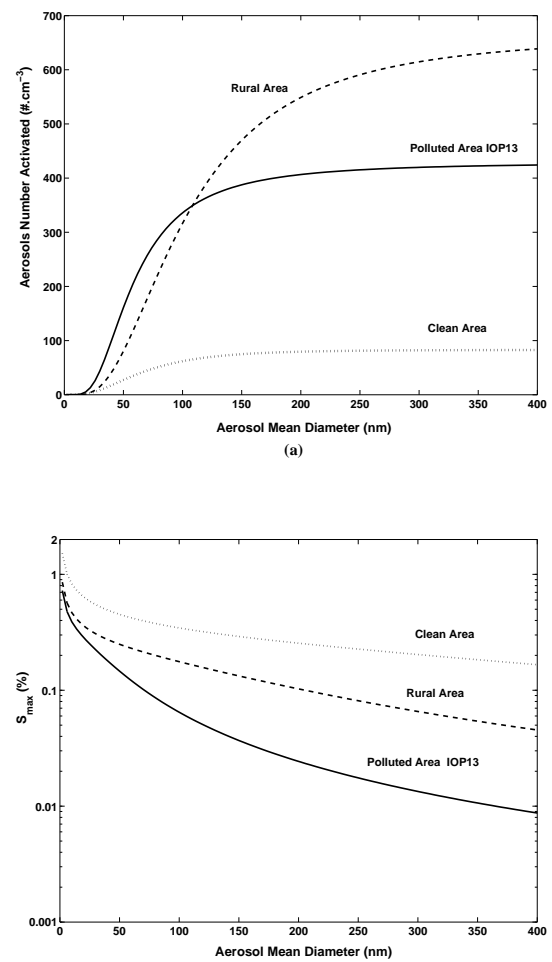

Fig. 4. Number of activated aerosols (a) and maximum supersaturation (b) as functions of the aerosol median diameter for the three types of aerosol number concentration described in Fig. 3 with the Reference chemical composition of IOP 13. The radiative cooling rate is $-10 \mathrm{~K} \mathrm{~h}^{-1}$. The geometric standard deviation is 1.59 .

18009
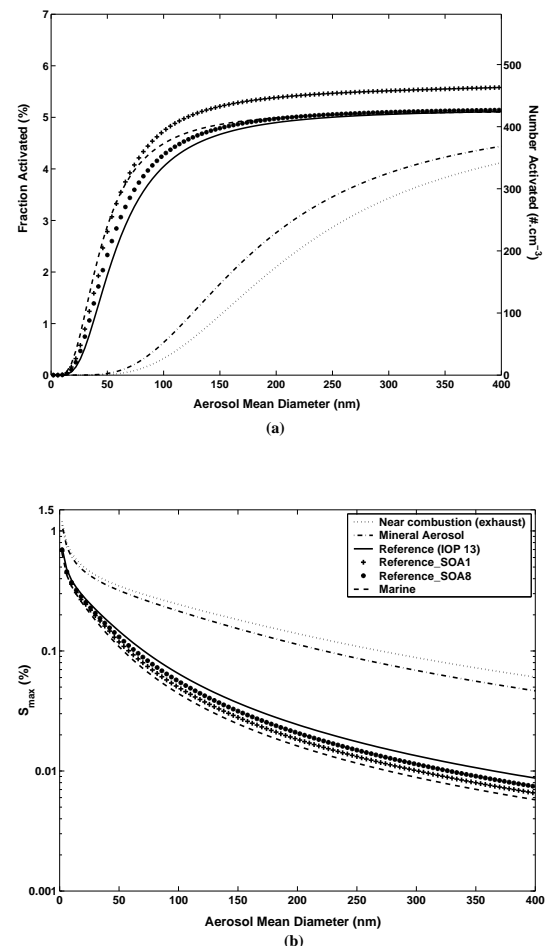

Fig. 5. (a) Fraction of activated aerosols and corresponding number of activated aerosols and (b) maximum supersaturation as functions of the aerosol median diameter for the six aerosol chemical compositions (see Table 3), for a cooling rate of $-10 \mathrm{Kh}^{-1}$, the aerosol number concentration and the geometric standard deviation are respectively 8300 particle $\mathrm{cm}^{-3}$ and 1.59 . 


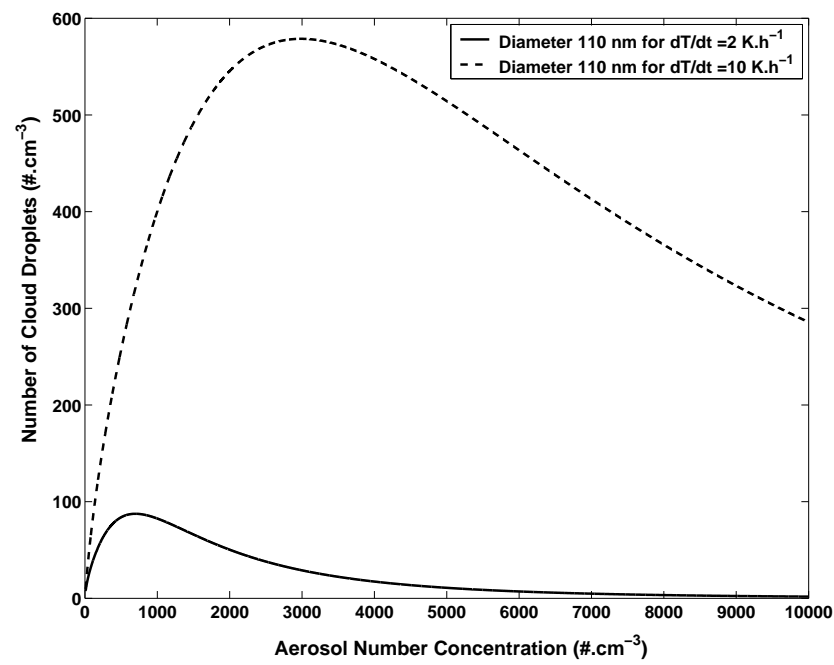

Fig. 6. Number of activated aerosols as function of aerosol number concentration for a cooling rate of $-2 \mathrm{Kh}^{-1}$ (solid line) and $-10 \mathrm{Kh}^{-1}$ (dashed line) with the Reference chemical composition. The aerosol median diameter and the geometric standard deviation are $110 \mathrm{~nm}$ and 1.59 respectively.
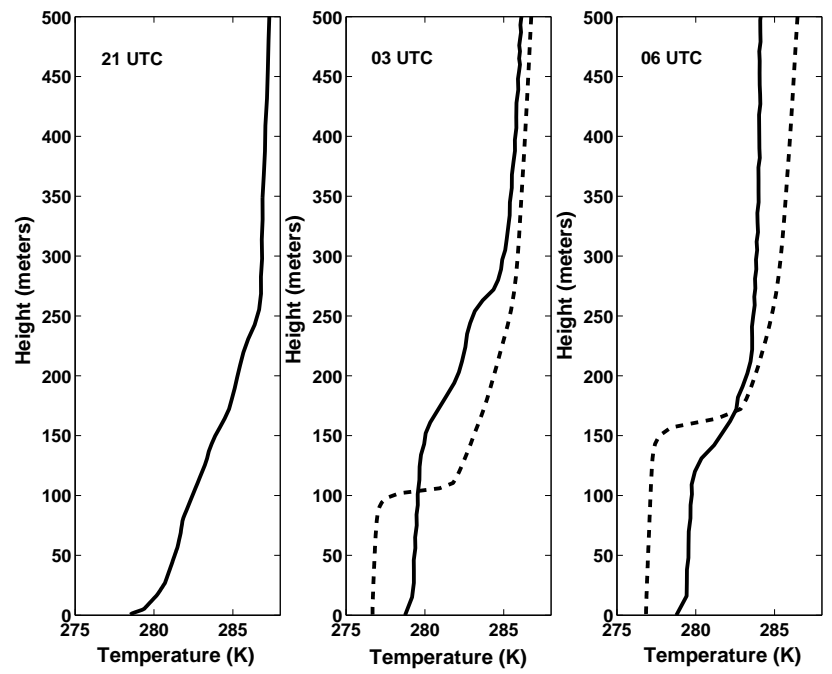

Fig. 7. Observed (solid line) and simulated (dashed line) vertical profiles of potential temperature at 21:00, 03:00 and 06:00 UTC. 


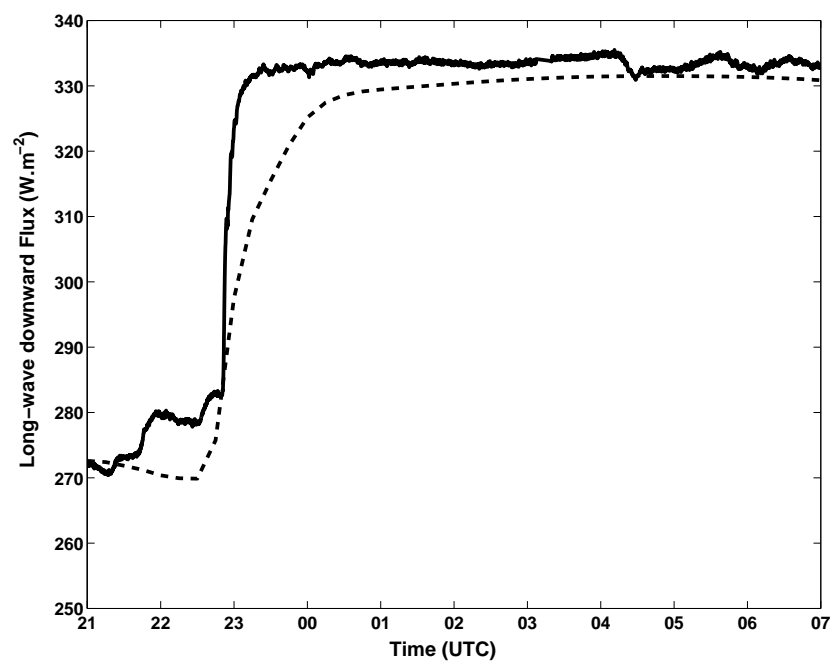

Fig. 8. Evolution of long-wave downward radiative flux observed (solid line) and simulated (dashed line) at $2 \mathrm{~m}$.

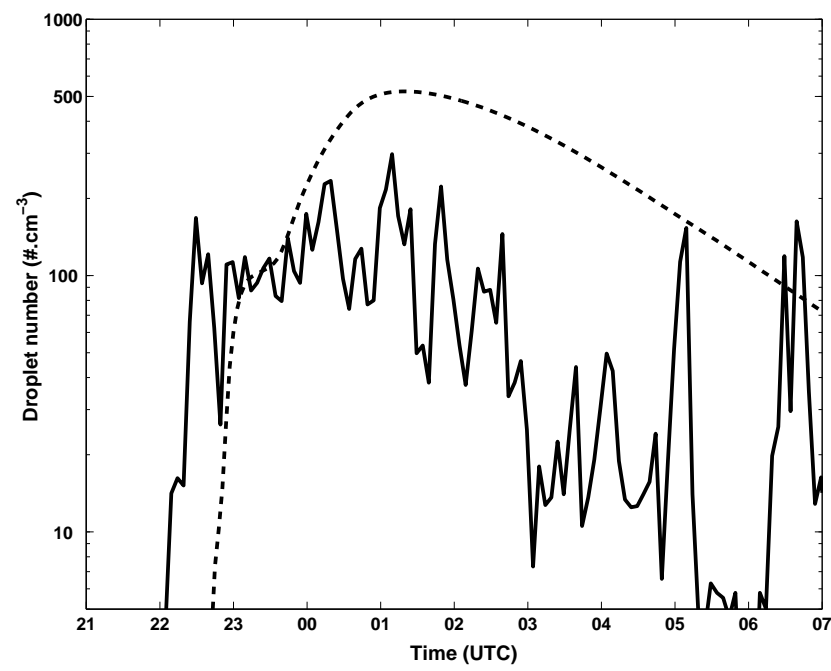

Fig. 9. Evolution of cloud droplets number concentration observed (solid line) and simulated (dashed line) at $2 \mathrm{~m}$. 

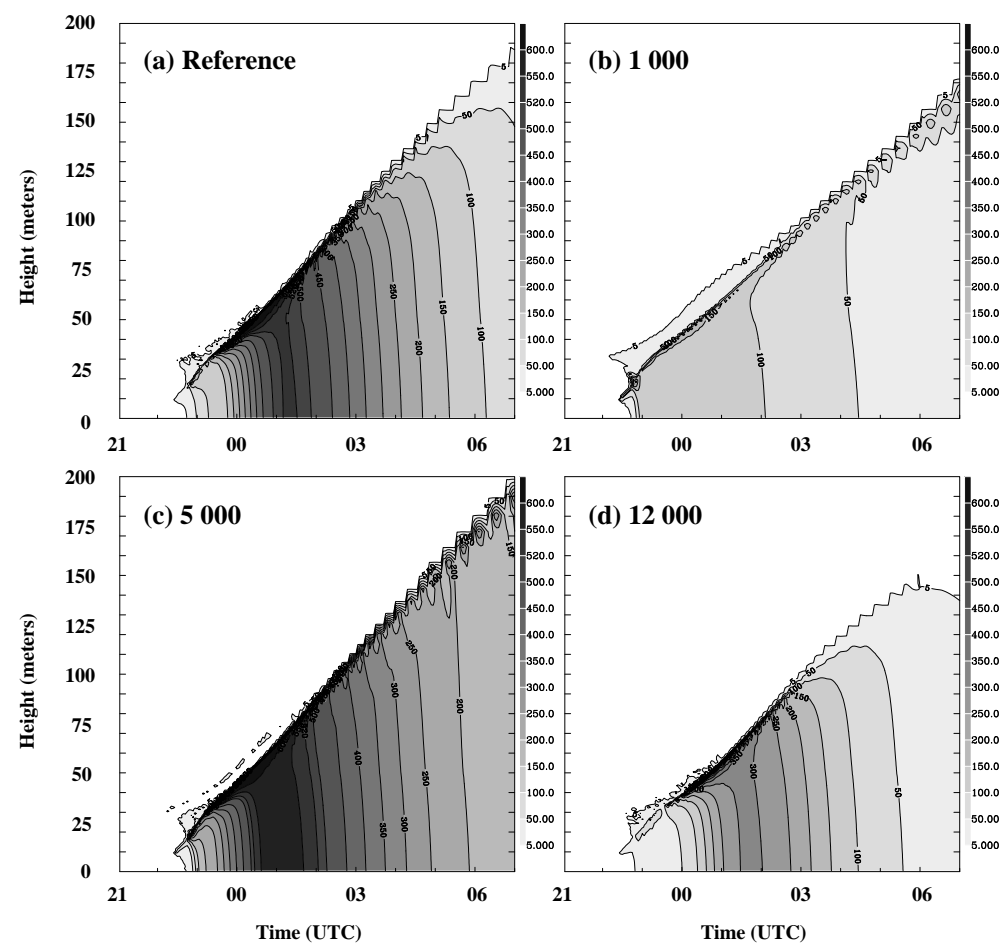

Fig. 10. Cloud droplet number concentration $\left(\mathrm{cm}^{-3}\right)$ for the four sensitivity cases for an aerosol number concentration in accumulation mode of $8300 \mathrm{~cm}^{-3}$ (reference) (a), $1000 \mathrm{~cm}^{-3}$ (b), $5000 \mathrm{~cm}^{-3}$ (c) and $12000 \mathrm{~cm}^{-3}$ (d) as functions of height and time.

18015

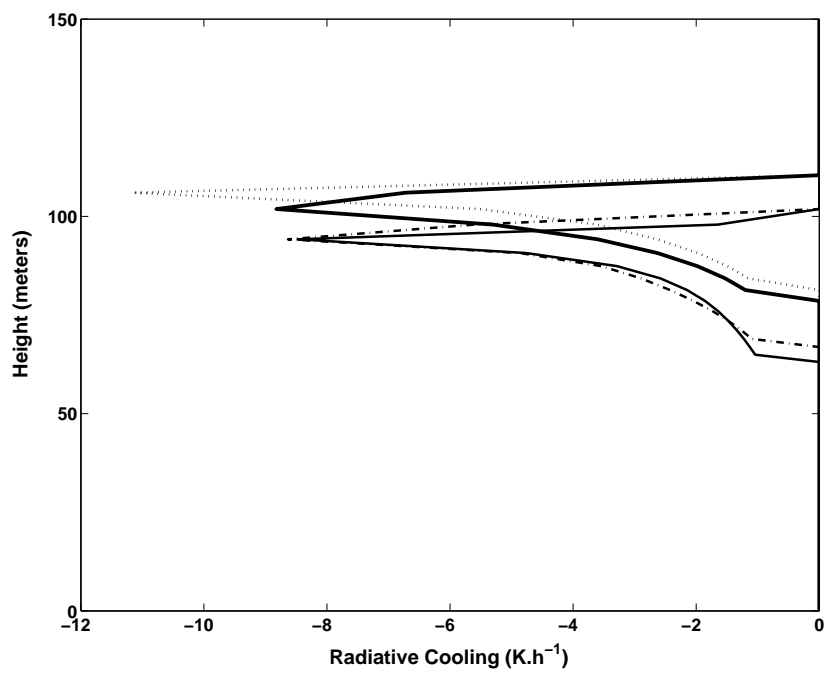

Fig. 11. Example of simulated vertical profile of radiative cooling rate $\left(\mathrm{Kh}^{-1}\right)$ at $03: 00$ UTC for the four sensitivity cases: $1000 \mathrm{~cm}^{-3}$ (solid line), $5000 \mathrm{~cm}^{-3}$ (dotted line), $8300 \mathrm{~cm}^{-3}$ (reference, thick solid line) and 12000 particle $\mathrm{cm}^{-3}$ (dash-dot line). 

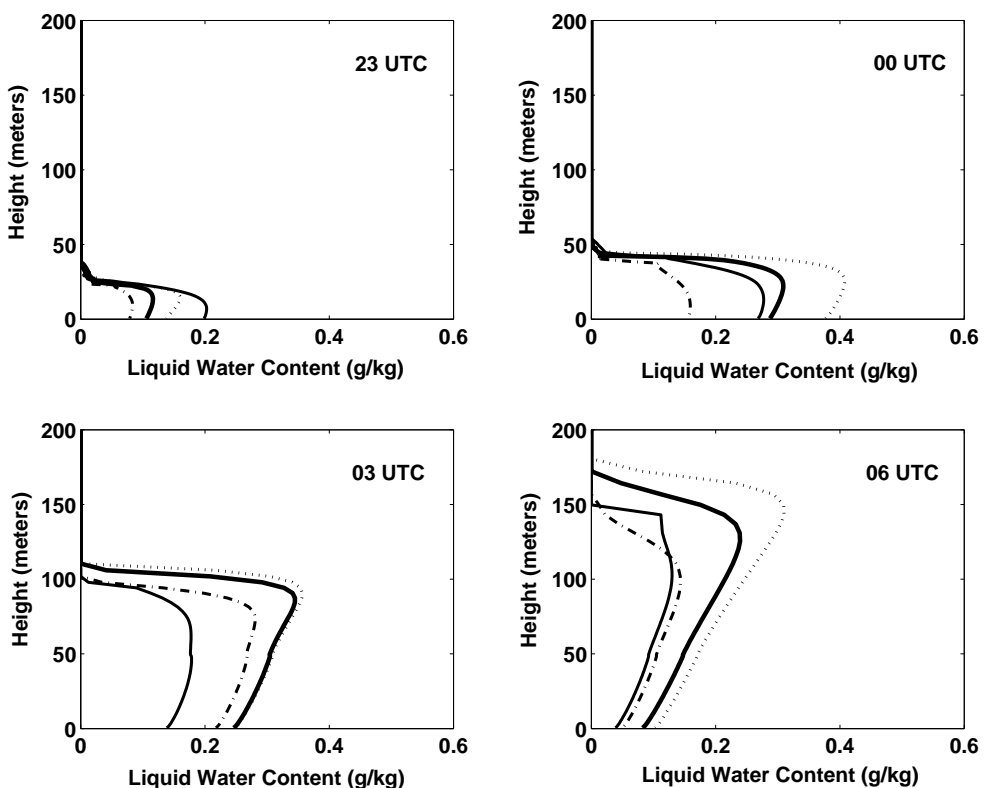

Fig. 12. Vertical profiles of LWC $\left(\mathrm{g} \mathrm{kg}^{-1}\right)$ at 23:00, 00:00, 03:00 and 06:00 UTC for the four sensitivity cases: $1000 \mathrm{~cm}^{-3}$ (solid line), $5000 \mathrm{~cm}^{-3}$ (dotted line), $8300 \mathrm{~cm}^{-3}$ (reference, thick solid line) and 12000 particles $\mathrm{cm}^{-3}$ (dash-dot line).

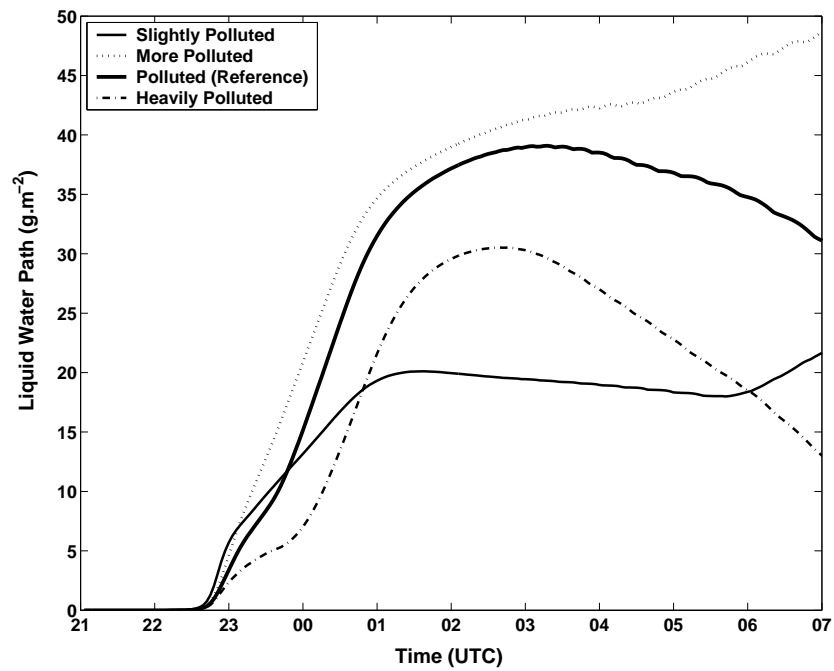

Fig. 13. Evolution of the LWP $\left(\mathrm{g} \mathrm{m}^{-2}\right)$ for the four sensitivity cases: slightly polluted 1000 aerosols per $\mathrm{cm}^{-3}$ (solid line), more polluted 5000 aerosols per $\mathrm{cm}^{-3}$ (dotted line), polluted 8300 aerosols per $\mathrm{cm}^{-3}$ (reference) (thick solid line) and heavily polluted 12000 aerosols per $\mathrm{cm}^{-3}$ (dash-dot line) for the accumulation mode during the simulation. 


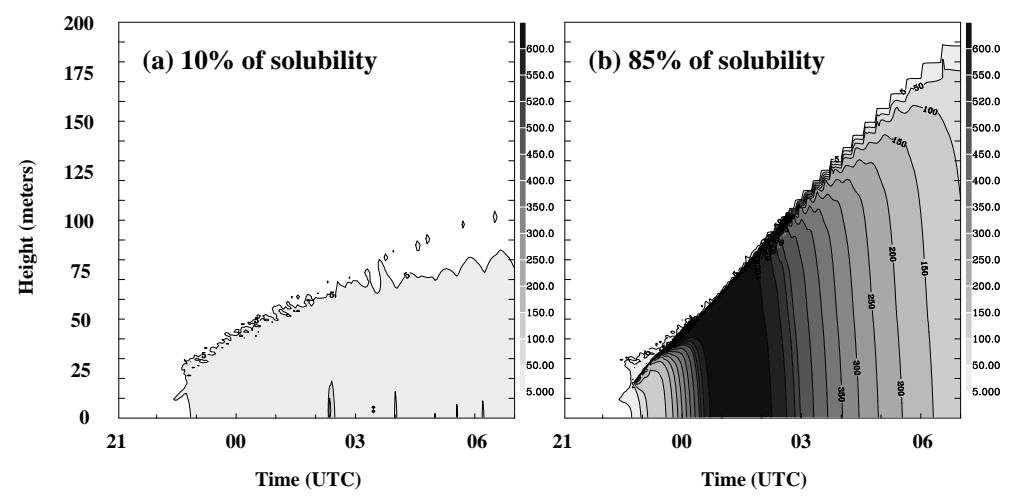

Fig. 14. Cloud droplet concentration $\left(\mathrm{cm}^{-3}\right)$ for the aerosol chemical composition with $10 \%$ solubility (Mineral Aerosol case) (a) and $85 \%$ solubility (Reference_SOA1) (b) as functions of height and time. 